Research Article

\title{
Fusobacterium nucleatum Facilitates Apoptosis, ROS Generation, and Inflammatory Cytokine Production by Activating AKT/MAPK and NF- $\kappa$ B Signaling Pathways in Human Gingival Fibroblasts
}

\author{
Wenyan Kang, ${ }^{1,2,3}$ Zhilong Jia, ${ }^{4}$ Di Tang $\mathbb{D}^{1,2}$ Zhanwei Zhang $\mathbb{D}^{1,2}$ Hui Gao, ${ }^{1,2,5}$ Kunlun He, \\ and Qiang Feng $\mathbb{D}^{1,2,6}$ \\ ${ }^{1}$ Shandong Provincial Key Laboratory of Oral Tissue Regeneration \& Shandong Engineering Laboratory for Dental Materials and \\ Oral Tissue Regeneration, School of Stomatology, Shandong University, Jinan, Shandong 250012, China \\ ${ }^{2}$ Department of Human Microbiome, School of Stomatology, Shandong University, Jinan, Shandong 250012, China \\ ${ }^{3}$ Department of Periodontology, School of Stomatology, Shandong University, Jinan, Shandong 250012, China \\ ${ }^{4}$ Beijing Key Laboratory for Precision Medicine of Chronic Heart Failure, Chinese PLA General Hospital, Beijing 100853, China \\ ${ }^{5}$ Department of Stomatology, Weifang People's Hospital, Weifang, Shandong 261042, China \\ ${ }^{6}$ State Key Laboratory of Microbial Technology, Shandong University, Qingdao, Shandong 266237, China
}

Correspondence should be addressed to Qiang Feng; fengqiang@sdu.edu.cn

Received 24 December 2018; Revised 24 May 2019; Accepted 2 June 2019; Published 13 October 2019

Academic Editor: José Luís García-Giménez

Copyright ( 2019 Wenyan Kang et al. This is an open access article distributed under the Creative Commons Attribution License, which permits unrestricted use, distribution, and reproduction in any medium, provided the original work is properly cited.

Fusobacterium nucleatum (F. nucleatum) plays key roles in the initiation and progression of periodontitis. However, the pathogenic effect of F. nucleatum on human oral tissues and cells has not been fully evaluated. In this study, we aimed to analyze the pathogenic effects of F. nucleatum on human gingival fibroblasts (GFs) and clarify the potential mechanisms. RNA-sequencing analysis confirmed that F. nucleatum significantly altered the gene expression of GF as the stimulation time increased. Cell counting and EdU-labeling assays indicated that F. nucleatum inhibited GF proliferation and promoted cell apoptosis in a time- and dosedependent manner. In addition, cell apoptosis, intracellular reactive oxygen species (ROS) generation, and proinflammatory cytokine production were dramatically elevated after F. nucleatum stimulation. Furthermore, we found that the AKT/MAPK and NF- $\kappa$ B signaling pathways were significantly activated by $F$. nucleatum infection and that a large number of genes related to cellular proliferation, apoptosis, ROS, and inflammatory cytokine production downstream of AKT/MAPK and NF- $\kappa$ B signaling pathways were significantly altered in F. nucleatum-stimulated GFs. These findings suggest that $F$. nucleatum inhibits GF proliferation and promotes cell apoptosis, ROS generation, and inflammatory cytokine production partly by activating the AKT/MAPK and NF- $\kappa$ B signaling pathways. Our study opens a new window for understanding the pathogenic effects of periodontal pathogens on the host oral system.

\section{Introduction}

Periodontal diseases are prevalent globally, with approximately $60 \%$ of the adult population suffering from mild, moderate, or aggressive periodontitis $[1,2]$. As a chronic inflammatory disease, periodontitis is characterized by the destruction of the gingiva, periodontal ligament, cementum, and alveolar bone and is initiated by the invasion of specific oral pathogens that colonize dental plaque biofilms on the tooth surface [3-5]. The pathogenesis of periodontitis is complex, and excessive tissue destruction occurs as a result of interactions between pathogenic bacteria and the host immune inflammatory response [3]. Previous studies have confirmed that periodontitis is commonly caused by gram- 
negative bacterial infection such as Porphyromonas gingivalis (P. gingivalis), Tannerella forsythia, and Aggregatibacter actinomycetemcomitans [6-9]. However, Fusobacterium nucleatum (F. nucleatum), which is also a fundamental periodontal pathogen, has not been extensively studied in the field of periodontics, and the pathogenicity of F. nucleatum has not been extensively studied in oral tissues and cells.

F. nucleatum, as a bridging bacterium, transfers critical periodontal pathogens to periodontal infectious sites and recruits and activates local immune cells, which results in tooth-supporting tissue destruction $[10,11]$. F. nucleatum has been identified as a high-frequency pathogen in periodontal disease [12] and many other infectious diseases, such as ventriculitis and brain abscesses [13], liver abscesses [14, 15], lung abscesses [16], septicemia-related infections [17], pelvic inflammatory disease [18], and intrauterine infections [19-21]. F. nucleatum attacks host tissues and obstructs the healing of damaged oral tissues by secreting large amounts of ammonia and butyrate $[22,23]$ and accelerates the initiation and progression of colorectal cancer by promoting tumor cell proliferation [24]. However, the effects of F. nucleatum on gingival fibroblast (GF) proliferation and apoptosis have not been reported.

The host response to pathogenic invasion is the determining factor of human health. As the first line of physical and chemical defense against infection, gingival epithelial cells release antimicrobial peptides such as human $\beta$-defensins to repress plaque biofilm formation, and activate innate and adaptive immune responses to protect the host from injury $[25,26]$. Pathogens penetrate the connective tissue, directly damage the periodontal supporting tissues, and then induce the destruction of the integrity of the gingival epithelium $[5,27]$. Human GFs, the predominant cell type of the periodontal connective tissue, are activated and recruited to sites of infection to regulate the occurrence and development of diseases [28-30]. It has been reported that GFs directly act on oral pathogens to defend against the progression of the infection by secreting various types of cytokines and chemokines, such as interleukin- (IL-) $1 \beta$, IL-6, IL-8, and tumor necrosis factor- (TNF-) $\alpha[31,32]$. Cytokine production is a crucial component for host defense against pathogenic invasion $[31,32]$. A previous study confirmed that GFs showed no tolerance to bacterial stimulation and could continuously respond to exogenous stimuli and produce high levels of inflammatory cytokines [33]. However, the understanding of the pathogenic effects of $F$. nucleatum on inflammatory cytokine production by GFs and the potential mechanism has not been completely elucidated.

It has been reported that bacterial infection induces the mitochondrial electron transport for aerobic respiration and then dramatically elevates the intracellular reactive oxygen species (ROS) levels, which play critical roles in regulating cellular proliferation, apoptosis, and inflammatory response [34-36]. F. nucleatum has been shown to induce bladder cancer cell apoptosis through mediating ROS generation and mitochondrial dysfunction [34]. F. nucleatum enhances proinflammatory cytokine production by causing the impairment of autophagic flux in Caco-2 cells [35]. However, the effects of F. nucleatum on GF ROS generation remain unclear.
In this study, we aimed to explore the comprehensive gene expression profile of GFs over an F. nucleatum stimulation time course. We validated the effects of $F$. nucleatum on GF proliferation, apoptosis, intracellular ROS generation, and inflammatory cytokine production by biological experiments. Furthermore, we investigated the potential mechanism by which $F$. nucleatum regulated the biological properties of GFs according to the significantly enriched signaling pathways.

\section{Materials and Methods}

2.1. Human Subjects and Ethical Statements. This study was approved by the Medical Ethical Committee of the Stomatology School, Shandong University (Protocol Number: 20170101). Five healthy individuals aged 30-35 who underwent impacted tooth extraction at the Department of Oral and Maxillofacial Surgery, Stomatology Hospital of Shandong Province, were recruited. All individuals were informed about the research project and signed the informed consent form according to the Helsinki Declaration of 1975.

2.2. Cell Isolation and Culture. The excised gingival tissues were immediately immersed in Dulbecco's modified Eagle's medium (DMEM, HyClone, Logan, UT, USA) with 5\% antibiotics $(100 \mathrm{U} / \mathrm{ml}$ penicillin and $100 \mathrm{mg} / \mathrm{ml}$ streptomycin, Sigma-Aldrich, St Louis, MO, USA) and quickly transferred to the laboratory. Then, the free gingival tissue samples were washed, and the epithelium was removed. The samples were minced into small fragments of approximately $1-3 \mathrm{~mm}^{2}$ and digested for $2 \mathrm{~h}$ at $37^{\circ} \mathrm{C}$ by $3 \mathrm{mg} / \mathrm{ml}$ collagenase I (Sigma Aldrich) and $4 \mathrm{mg} / \mathrm{ml}$ Dispase II (Invitrogen, Carlsbad, CA, USA). The primary GFs were cultured with DMEM containing 20\% fetal bovine serum (FBS, Biological Industries, Kibbutz, Israel) at $37^{\circ} \mathrm{C}$ in a humidified atmosphere of $5 \%$ $\mathrm{CO}_{2}$. Cells were fed fresh medium every three days until the cell monolayer reached $80-90 \%$ confluence. GFs were trypsinized and passaged at a dilution ratio of $1: 3$ to expand the culture in $10 \%$ FBS medium. The fourth passage cells were used for the following experiments, and cells were cultured in 10\% FBS DMEM in all experiments.

2.3. RNA-Sequencing (RNA-Seq) Analysis. A total of 54 samples from 5 individuals were sequenced to analyze the gene expression at the whole genome level at BGI (Beijing Genomics Institute, Shenzhen, China) by RNA-seq (each individual sample included 1 sample at time point $0 \mathrm{~h} ; 5$ control samples at $2 \mathrm{~h}, 6 \mathrm{~h}, 12 \mathrm{~h}, 24 \mathrm{~h}$, and $48 \mathrm{~h}$ with no $F$. nucleatum treatment; and 5 experimental samples with $F$. nucleatum stimulation at multiplicity of infection (MOI) of 100 at the same time points; sufficient RNA could not be extracted from one treated sample at the $12 \mathrm{~h}$ time point). Total RNA was isolated, evaluated for quality, reversetranscribed to cDNA, and sequenced on the BGISEQ-500 platform. After a quality control (QC) step (Agilent 2100 Bioanalyzer, Santa Clara, California, USA), the clean reads were mapped to the reference genome (GRCh38) via hierarchical indexing for spliced alignment of transcripts (HISAT) (v2.0.4) [37]. Bowtie 2 (v2.2.5) [38] was used to map the clean 
reads to the reference transcripts, and the gene expression level for each sample was calculated by RSEM [39]. The correlation among all samples was detected by principal component analysis (PCA). Based on the gene expression level, DESeq2 and PoissonDis algorithms were used to detect the differentially expressed genes (DEGs) between the control groups and the F. nucleatum-treated groups by an absolute of log base 2 of fold change in DEGs $\geq 1$ and an adjusted $P$ value $(\%)<5 \%$. Gene ontology (GO) was used for screening and annotating DEGs. WEGO software [40] was used to generate the GO functional classification file. Pathway enrichment analysis of DEGs was performed based on the Kyoto Encyclopedia of Genes and Genomes (KEGG) database [41]. A Venn diagram was used to show the overlapping genes among the DEGs of each group. The protein-protein interaction network was generated by the STRING [42] website with default parameters. The Pathview [43] website was used to analyze the signaling pathway activation after $F$. nucleatum stimulation. In addition, Venn diagrams and heat maps were used to present the expression signatures of the DEGs involved in the GO biological processes, including cell proliferation (GO: 0008283), apoptotic process (GO: 0006915), response to reactive oxygen species (GO: 0000302), and defense response (GO: 0006952). The RNA sequence data have been deposited in the NCBI Gene Expression Omnibus (GEO, http://www.ncbi.nlm.nih.gov/geo/) and are accessible through GEO series accession number GSE118691.

2.4. Cell Proliferation Assay. GFs were seeded in 6-well $\left(1 \times 10^{5}\right.$ cells/well $)$ plates in growth medium with $10 \% \mathrm{FBS}$. Cells were left untreated or incubated with $F$. nucleatum at multiplicities of infection (MOIs) (F. nucleatum: cell of $10: 1,50: 1,100: 1,200: 1$, and $400: 1$ ). Cells were counted every other day using a hemocytometer (Corning, Corning, NY, USA) or an automated cell counter (Countstar, Shanghai, China). To assess the cell proliferation rate, cells were inoculated in 24 -well plates $\left(5 \times 10^{4}\right.$ cells/well $)$ and treated with the indicated concentration of F. nucleatum. The 5-ethynyl$2 '$-deoxyuridine labeling assay was used to evaluate the cell proliferation rate according to the instructions of an EdU Apollo DNA in vitro kit (RiboBio, Guangzhou, China). The experiment was performed in sextuplicate and repeated three times.

2.5. Cell Apoptosis and Viability Analysis. Cell apoptosis was analyzed according to the instructions of an Annexin VFITC/PI kit (Dojindo, Kumamoto, Japan). GFs were seeded in 6-well plates $\left(2 \times 10^{5}\right.$ cells/well $)$ and stimulated with different densities of $F$. nucleatum for 2, 6, 12, 24, 36, and $48 \mathrm{~h}$. Afterward, cells were trypsinized, washed with phosphatebuffered saline (PBS), stained with a PI-conjugated antiannexin $\mathrm{V}$ antibody for $15 \mathrm{~min}$ at room temperature in the dark, and then subjected to flow cytometry; the data were analyzed by Accuri C6 Plus software (Becton Dickinson, Franklin Lakes, NJ, USA). Cell viability was detected by trypan blue (Solarbio) staining. GFs treated with $4 \%$ formaldehyde were used as a positive control, and untreated cells were used as a negative control. Trypan blue was added to the monolayers at a $1: 10$ dilution and incubated for
$10 \mathrm{~min}$. The cells were observed immediately under the microscope and photographed (Olympus, Tokyo, Japan). The experiment was performed in triplicate and repeated three times.

2.6. Measurement of Intracellular ROS. Intracellular ROS levels were detected by a $2^{\prime}, 7^{\prime}$-dichlorofluorescein diacetate (DCFH-DA) assay. GFs were seeded in 6-well plates and treated with $F$. nucleatum at the above-mentioned MOIs for $2,6,12,24,36$, and $48 \mathrm{~h}$. Cells were incubated with DCFHDA $(1: 1000)$ for $20 \mathrm{~min}$ at $37^{\circ} \mathrm{C}$ in a cell incubator in the dark. Flow cytometry (Becton Dickinson) was used to determine the intracellular ROS production. The flow cytometry data were analyzed by Accuri C6 Plus software. Each experiment was performed in triplicate and repeated three times.

2.7. RNA Isolation and Quantitative Real-Time Polymerase Chain Reaction ( $q R T-P C R$ ). GFs were seeded in 6-well plates and cultured with $F$. nucleatum. GFs were collected at 6 different time points $(0 \mathrm{~h}, 2 \mathrm{~h}, 6 \mathrm{~h}, 12 \mathrm{~h}, 24 \mathrm{~h}$, and $48 \mathrm{~h})$, and total RNA was extracted with TRIzol ${ }^{\circledR}$ (CWBIO, Beijing, China). The mRNA concentration was determined using an ultramicro spectrophotometer (Thermo Fisher Scientific, Waltham, MA, USA). One microgram of mRNA was reverse-transcribed to cDNA using a HiFiScript cDNA Synthesis kit (CWBIO). qRT-PCR was performed with an UltraSYBR Mixture (CWBIO) on a LightCycler 96 RealTime PCR System (Roche, Basel, Switzerland) in triplicate. Briefly, the hot start enzyme was activated $\left(95^{\circ} \mathrm{C}\right.$ for $10 \mathrm{~min}$ ), and the cDNA was then amplified for 45 cycles of denaturation at $95^{\circ} \mathrm{C}$ for $10 \mathrm{~s}$, annealing at $60^{\circ} \mathrm{C}$ for $30 \mathrm{~s}$ and extension at $72^{\circ} \mathrm{C}$ for $32 \mathrm{~s}$. Data were analyzed using the $2^{(-\Delta \Delta \mathrm{Ct})}$ method. The sequences of the primers for amplification are shown in Supplementary Table 1. The experiment was performed in triplicate and repeated three times.

2.8. Enzyme-Linked Immunosorbent Assay (ELISA). GFs were seeded in 6-well plates and treated with $F$. nucleatum at an MOI of $100: 1$. Cell culture supernatants were collected and centrifuged at $12,000 \mathrm{rpm}$ for $5 \mathrm{~min}$ at $4^{\circ} \mathrm{C}$. The levels of secreted IL-6, IL- 8 , IL- $1 \beta$, and TNF- $\alpha$ protein were measured by ELISA (BioLegend, San Diego, CA, USA) according to the manufacturer's instructions. The optical density values were measured by a microplate reader at $450 \mathrm{~nm}$ and $570 \mathrm{~nm}$, and the $570 \mathrm{~nm}$ values were subtracted from the absorbance at $450 \mathrm{~nm}$ in the subsequent data analysis. The experiment was performed in triplicate and repeated three times.

2.9. Western Blot Assay. GFs with or without F. nucleatum stimulation were harvested with a RIPA lysis buffer containing $1 \%$ protease inhibitors and $1 \%$ phosphatase inhibitors (Solarbio, Beijing, China). Protein concentrations were measured according to bicinchoninic acid (BCA) assays, and proteins $(20 \mu \mathrm{g} / \mathrm{lane})$ were separated to $10 \%$ sodium dodecyl sulfate-polyacrylamide gel electrophoresis (SDS-PAGE) gels and transferred to polyvinylidene fluoride (PVDF) membranes (Millipore, Billerica, MA, USA). Membranes were blocked with $5 \%$ nonfat milk for $1 \mathrm{~h}$, incubated with primary antibodies overnight at $4^{\circ} \mathrm{C}$, and then incubated with horseradish peroxidase-conjugated secondary antibodies (1:10 
000; Proteintech, Chicago, IN, USA) for $1 \mathrm{~h}$ at room temperature. The protein bands were visualized with enhanced chemiluminescence reagents (Millipore) and scanned using an extra-sensitive imager (Amersham Imager 600; GE Healthcare Life Sciences, Pittsburgh, PA, USA). ImageJ 1.44 software (NIH, Bethesda, Maryland, USA) was used to quantify the protein expression levels. The primary antibodies and dilution ratio were as follows: rabbit anti-NF- $\kappa \mathrm{B}$ p65 (1:10000; Abcam, Cambridge, UK), rabbit anti-phosphoNF- $\kappa$ B p65 (1:1000; Abcam), rabbit anti-I $\kappa \mathrm{B} \alpha$ (1:5000; Abcam), rabbit anti-phospho-I $\kappa \mathrm{B} \alpha(1: 1000 ; \mathrm{Abcam})$, rabbit anti-p38 (1:1000; Cell Signaling Technology, Danvers, MA, USA), rabbit anti-phospho-p38 (1:1000; Cell Signaling Technology), rabbit anti-JNK $(1: 1000$; Cell Signaling Technology), rabbit anti-phospho-JNK (1:1000; Cell Signaling Technology), rabbit anti-ERK1/2 (1:1000; Cell Signaling Technology), rabbit anti-phospho-ERK1/2 (1:1000; Cell Signaling Technology), rabbit anti-AKT ( $1: 1000$; Cell Signaling Technology), rabbit anti-phospho-AKT ( $1: 1000$; Cell Signaling Technology), rabbit anti-p53 (1:1000; Abcam), and rabbit anti-phospho-p53 (1:1000;Abcam). The experiment was performed in triplicate and repeated three times.

2.10. Cell Immunocytochemistry Assay. To detect F. nucleatum-induced nuclear translocation of NF- $\kappa \mathrm{B}$ p65 and pp65, GFs were seeded in coverslip containing 24-well plates at a density of $2 \times 10^{4}$ cells/well and treated with or without F. nucleatum for $5 \mathrm{~min}$ to $120 \mathrm{~min}$. Cells were fixed with $4 \%$ paraformaldehyde and blocked with $10 \%$ normal goat serum in PBS for $1 \mathrm{~h}$. Then, cells were incubated with primary antibodies against p65 and p-p65 overnight at $4{ }^{\circ} \mathrm{C}$. The next day, the cells were incubated with an Alexa Fluor 594-conjugated goat anti-rabbit IgG secondary antibody $(1: 500)$ in the dark for $1 \mathrm{~h}$, and the nuclei were visualized using 2-(4-amidinophenyl)-6-indolecarbamidine dihydrochloride (DAPI) for $5 \mathrm{~min}$. The images were captured by fluorescence microscopy (Olympus BX53, Tokyo, Japan). The experiment was performed in triplicate and repeated three times.

2.11. Statistical Analysis. All data were expressed as the mean \pm standard deviation (SD). Tests were analyzed using GraphPad Prism software (version 6, Software MacKiev, Boston, MA, USA), and differences among more than two groups were analyzed by one-way or two-way ANOVA followed by Tukey's honestly significant difference (HSD) comparison test. Variance between two groups was compared by a multiple $t$-test. $P<0.05$ was considered indicative of statistical significance.

\section{Results}

3.1. RNA-Seq Analysis of F. nucleatum-Stimulated GFs over Time. To better understand the global responses of GFs to F. nucleatum infection over time, we performed a genomewide transcriptome analysis by RNA-seq to determine the global changes in gene expression. A total of $100 \mathrm{~Gb}$ of sequence data was generated from 54 samples, and 23.90 million reads for each sample were generated on average (Supplementary Table 2). After QC, the clean reads were mapped to the reference genomes and transcripts with mapping percentages of $94.40 \%$ and $87.67 \%$, respectively (Supplementary Table 3 and Supplementary Table 4). A total of 18691 genes were detected, and the expression levels were calculated with RSEM (data can be obtained through GSE118691). The correlation analysis of the PCA on the whole-genome gene expression levels showed that the normal cells were relatively stable, while the F. nucleatumstimulated GFs gradually deviated from normal conditions as the stimulus time increased (Supplementary Figure 1). These results suggest that the effect of $F$. nucleatum stimulation on GFs may accumulate over time.

To characterize the DEGs influenced by F. nucleatum, the gene expression profiles of normal GFs versus infected cells at $2,6,12,24$, and $48 \mathrm{~h}$ were compared at each time point. Approximately 228, 374, 616, 1208, and 1334 genes were found to be upregulated, and $28,147,448,1302$, and 2145 genes were downregulated at 2, 6, 12,24, and $48 \mathrm{~h}$, respectively (Figure 1(a)). The overlap analysis of the DEGs among the 5 time points identified that 62 genes were differentially expressed between nonstimulated and F. nucleatum-stimulated GFs across the entire time course, and the number of DEGs continuously increased as the stimulation time increased (Figure 1(b)). These results suggest that the response of GFs to $F$. nucleatum infection increases over time, and a longer duration $F$. nucleatum stimulation might induce more side-effects than a short duration infection.

The heat map showed that the gene expression levels of 62 DEGs were upregulated and that some of these genes, such as IL-6, IL-1 $\beta$, CCL2, CXCL2, CXCL8, and CSF3, are closely associated with host defense responses to bacterial infection (Figure 1(c)). The KEGG annotation showed that the top 5 enriched pathways of these DEGs are immune-associated, namely, the TNF-signaling pathway, IL-17 signaling pathway, rheumatoid arthritis, NF- $\kappa \mathrm{B}$ signaling pathway, and NOD-like receptor signaling pathway (Figure $1(\mathrm{~d})$ ). The protein-protein interaction network of 62 DEGs showed the potentially complex interaction relationship among these genes (Figure 1(e)).

The GO analysis confirmed that the 62 DEGs are involved in host defense to bacterial infection and cell growth pathways, such as cellular process, response to stimulus, regulation of biological process, immune system process, response to bacterium, and cell proliferation (Supplementary Figure 2), and the top five enriched biological process GO terms for the 62 DEGs are shown in Supplementary Table 5.

3.2. F. nucleatum Inhibits the Proliferation of GFs. To study the effect of $F$. nucleatum on the proliferation of GFs, we applied a cell counting assay and EdU-labeling assay to quantify the cell proliferation rate over 5 days of $F$. nucleatum stimulation at MOIs of 10 and 100. The cell counting assay showed that $F$. nucleatum significantly inhibited the proliferation of GFs in a time- and dose-dependent manner (Figures 2(a) and 2(b)). To further test the inhibitory effect of different $F$. nucleatum concentrations, GFs stimulated with F. nucleatum at MOIs of 10, 50, 100, 200, and 400 were quantified at 3 time points over 5 days. The results showed that the inhibitory effect aggrandized with the increase of 


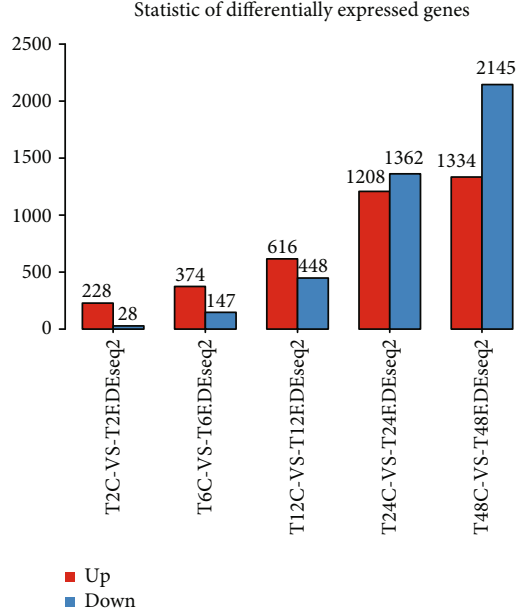

(a)

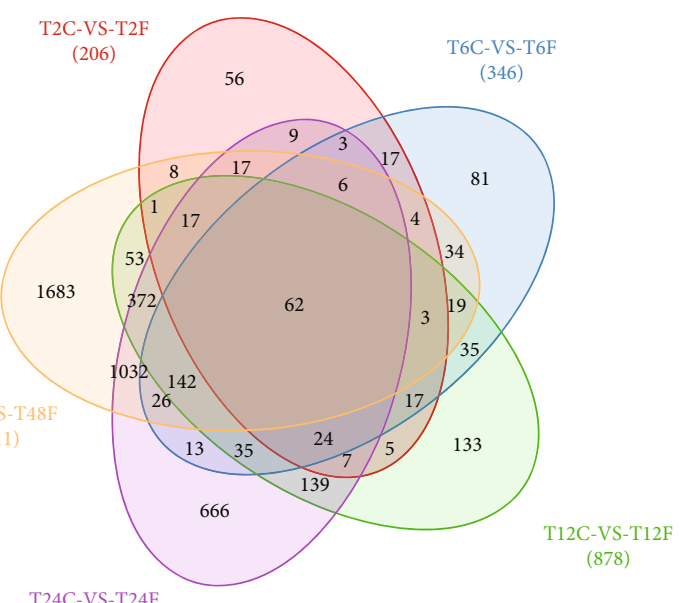

(b)

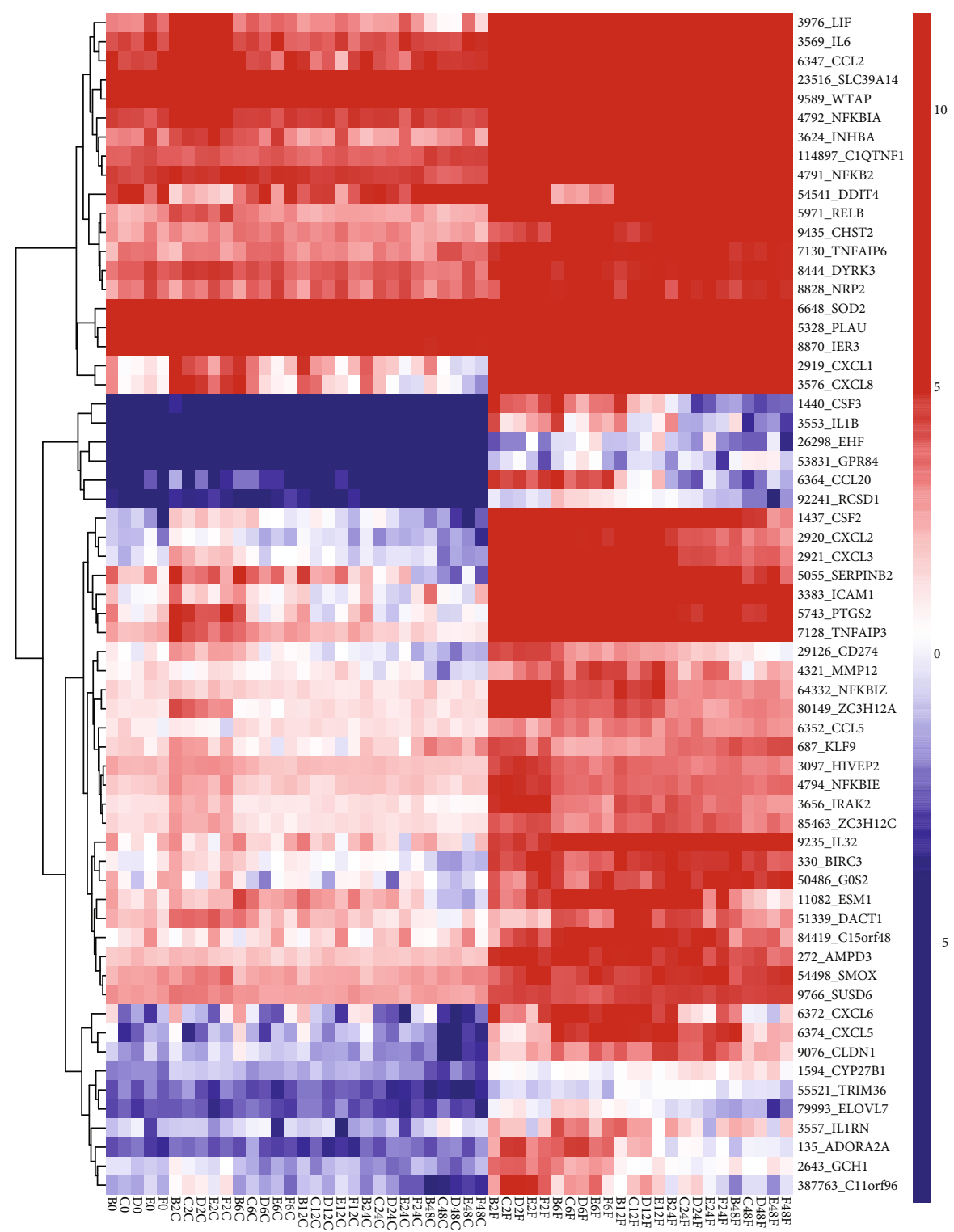

(c)

FIgUre 1: Continued. 


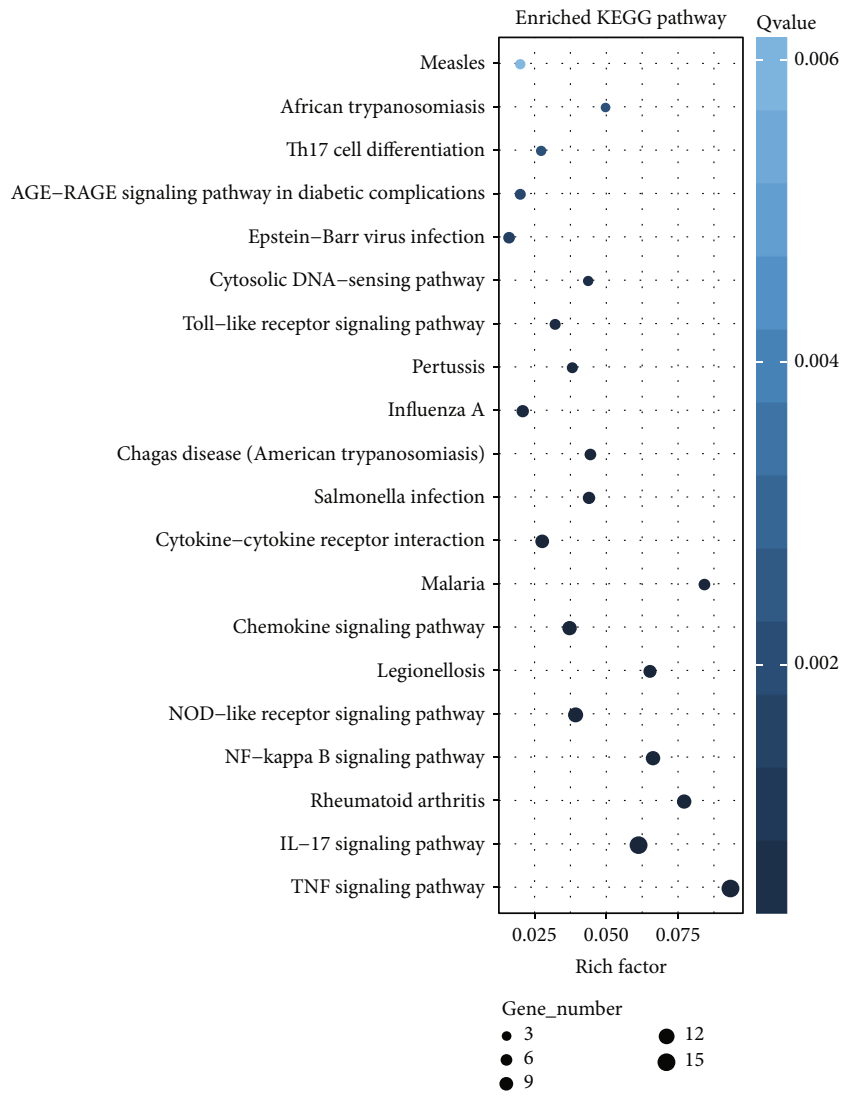

(d)

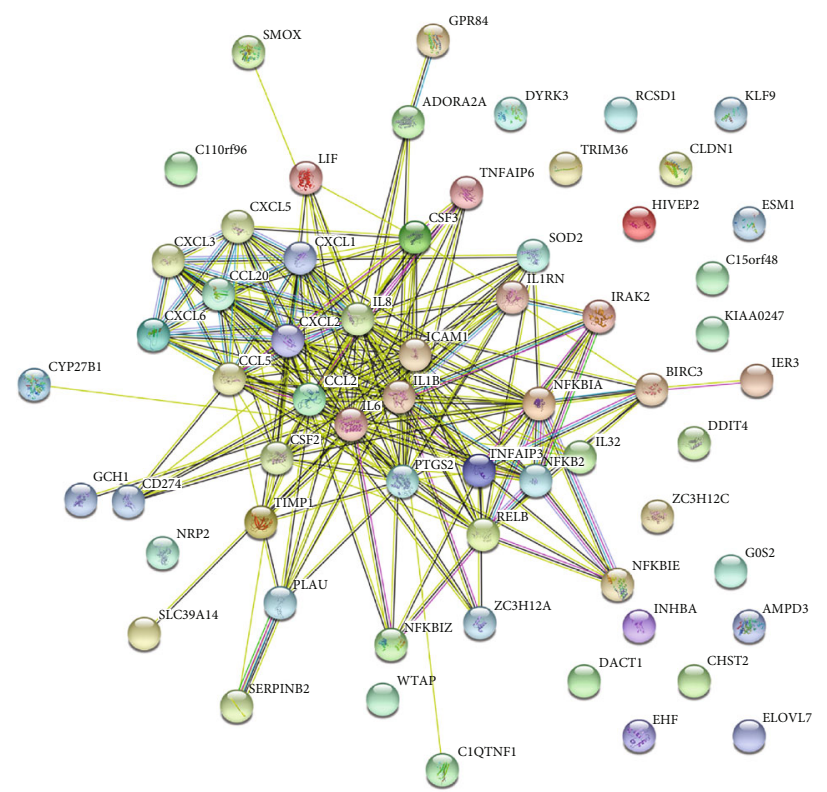

(e)

FIGURE 1: RNA-sequencing analysis of GFs stimulated with F. nucleatum (MOI of 100). (a) The number of DEGs in 54 samples after F. nucleatum stimulation at $2 \mathrm{~h}, 6 \mathrm{~h}, 12 \mathrm{~h}, 24 \mathrm{~h}$, and $48 \mathrm{~h}$. (b) Venn diagram summarizing the overlapping DEGs among the five time points. (c) Heat map of the 62 overlapping DEGs. (d) KEGG enrichment analysis of the 62 overlapping DEGs. (e) Network of 62 overlapping DEGs after F. nucleatum stimulation at $2 \mathrm{~h}, 6 \mathrm{~h}, 12 \mathrm{~h}, 24 \mathrm{~h}$, and $48 \mathrm{~h}$.

F. nucleatum concentration, and the high concentration of $F$. nucleatum (MOI of 400) directly blocked the cell growth (Figure 2(c)). The EdU-labeling assay demonstrated that
F. nucleatum significantly decreased the number of GFs and reduced the cell proliferation rate after $24 \mathrm{~h}$ of stimulation (Figure 2(d)-2(f)). The DEGs of the 54 samples 


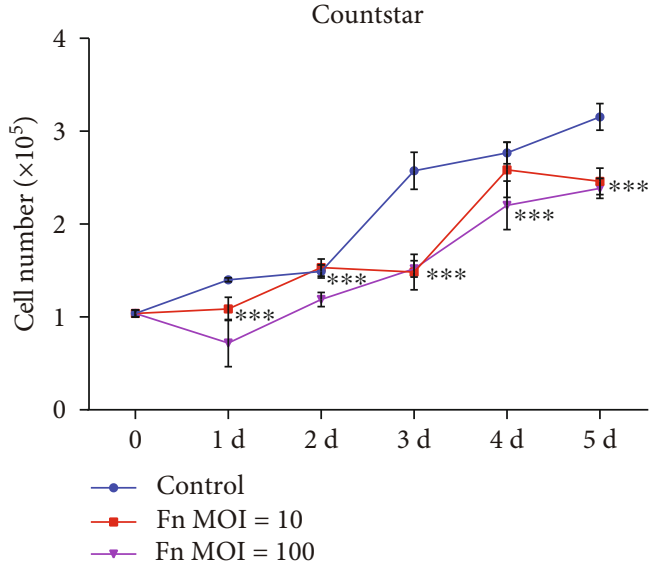

(a)

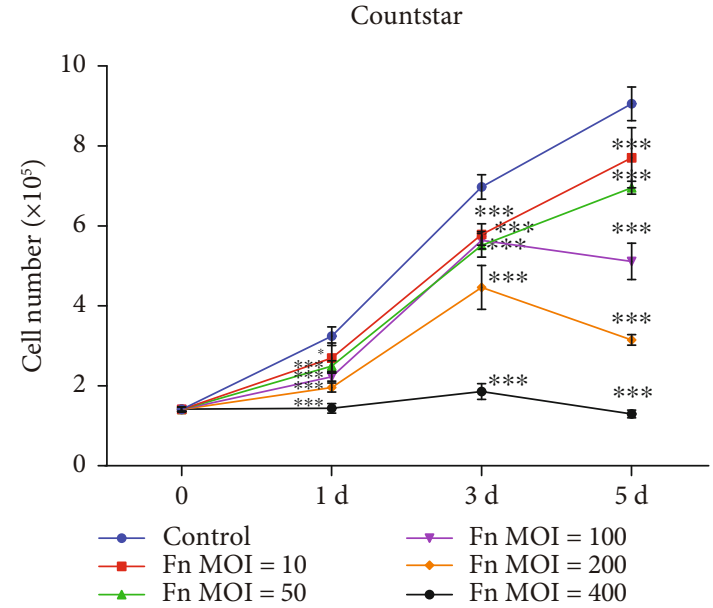

(c)

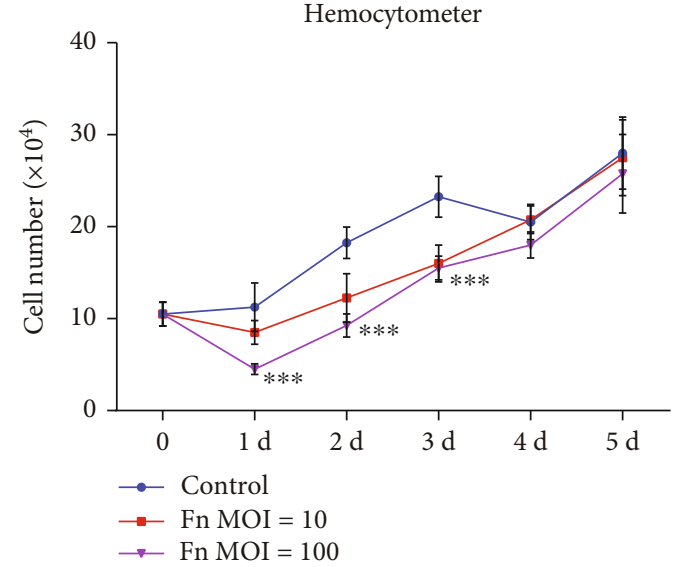

(b)

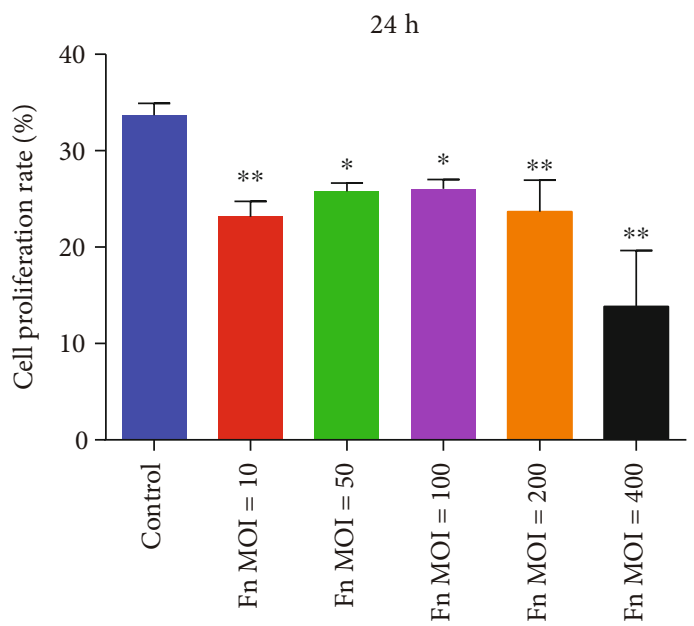

(d)

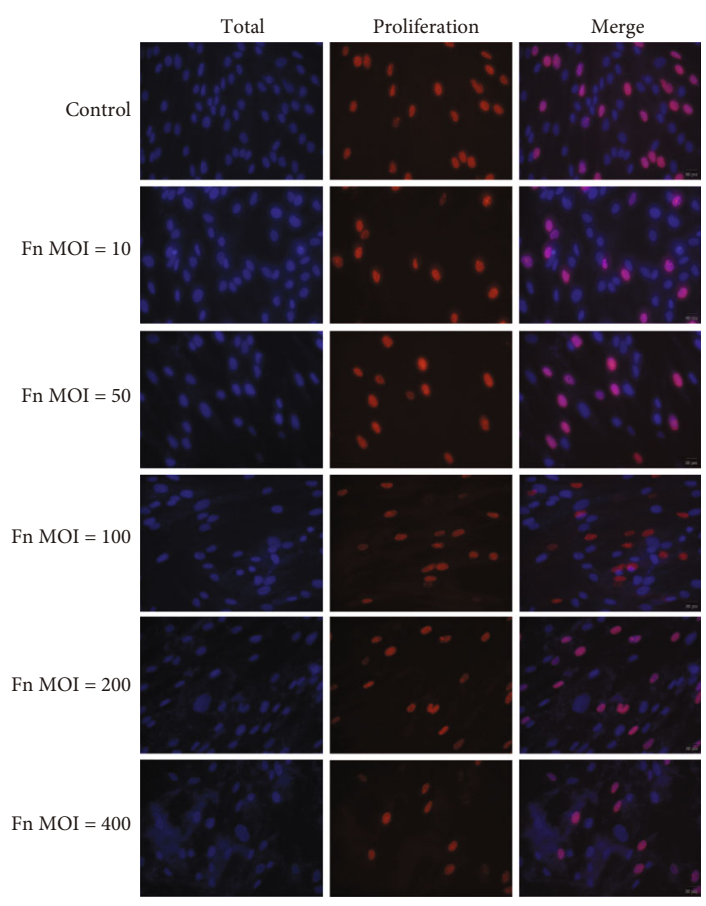

(e)

FIgUre 2: Continued. 


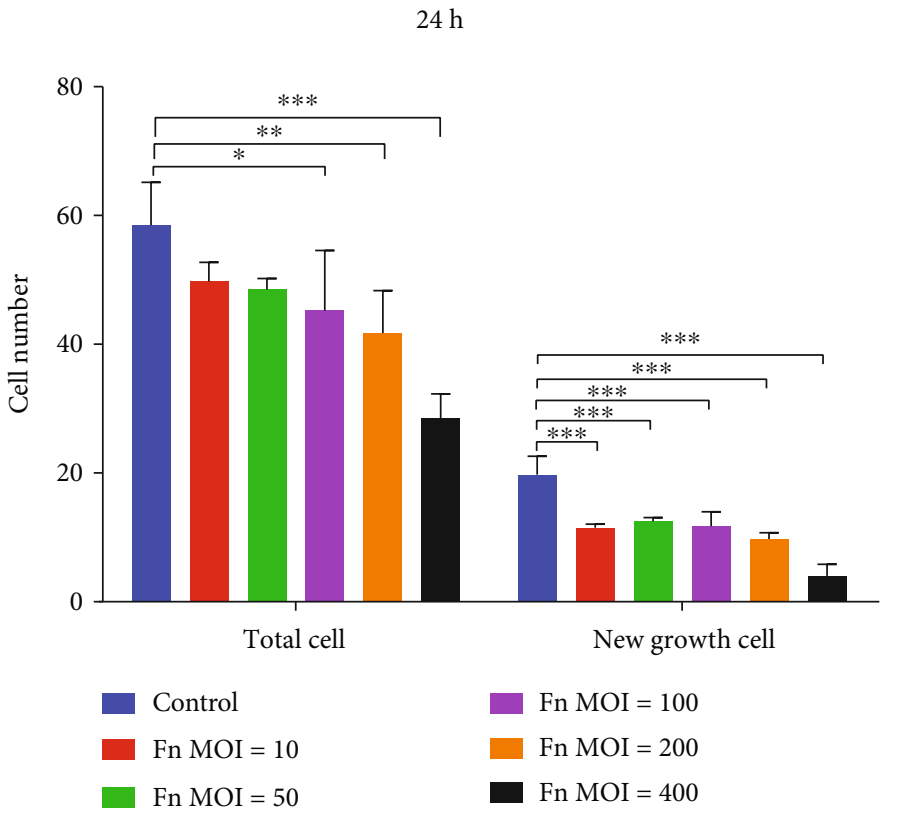

(f)
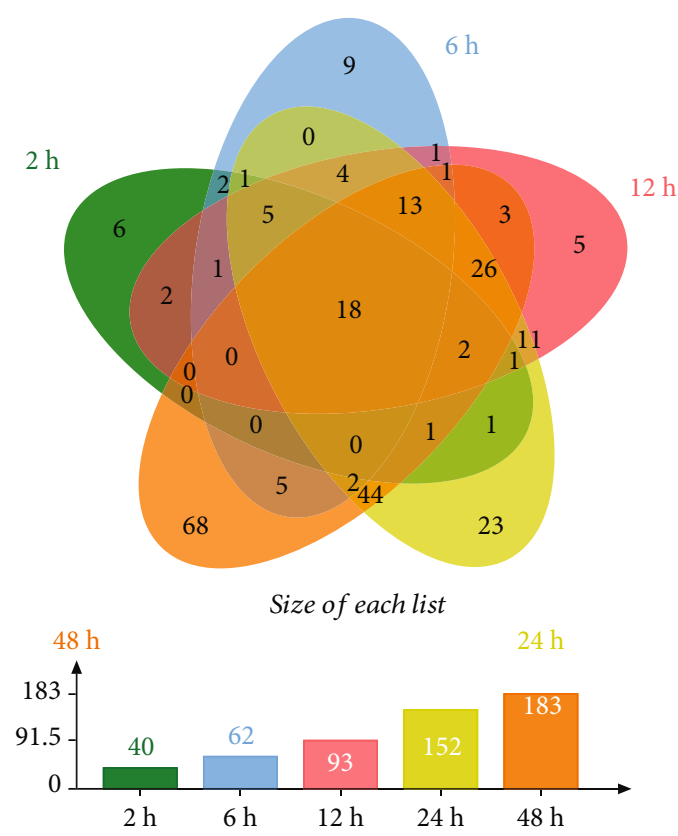

$(\mathrm{g})$

FIGURE 2: Effects of F. nucleatum on cell proliferation. Cell numbers of GFs detected by an electronic cell counter (a) and hemocytometer (b) with or without $F$. nucleatum stimulation at MOIs of 10 and $100(n=6)$. (c) Number of GFs detected by electronic cell counter after $F$. nucleatum stimulation (MOIs of $0,10,50,100,200$, and $400, n=6)$. (d) Cell proliferation rate of GFs detected by EdU assay $(n=6)$. (e) EdU assay of GFs after F. nucleatum stimulation (MOIs of 0, 10, 50, 100, 200, and 400) at $24 \mathrm{~h}$. Scale bar: $20 \mu \mathrm{m}$. NC: negative control; PC: positive control. (f) Statistical results of total and new cell growth after EdU labeling $(n=6)$. (g) Venn diagram of cell proliferationrelated DEGs from the GO biological process analysis among the five time points. All data are shown as the mean \pm SD. Statistical analyses were performed by one-way (d) and two-way (a, b, c, f) ANOVA with Tukey's multiple-comparison test. ${ }^{*} P<0.05$, ${ }^{* *} P<0.01$, and ${ }^{* * *} P<0.001$ compared with the Control.

enriched in the cell proliferation pathway (GO: 0008283) were compared using an overlap analysis, and the results indicated that the number of cell proliferation-related DEGs continuously increased as the F. nucleatum stimulation time increased; $40,62,93,152$, and 183 genes were detected at $2 \mathrm{~h}$, $6 \mathrm{~h}, 12 \mathrm{~h}, 24 \mathrm{~h}$, and $48 \mathrm{~h}$, respectively, and 18 DEGs, including CCL2, SOD2, and NFKBIA, were consistently upregulated across all the time points (Figure 2(g) and Supplementary Figure 3). The above results suggest that $F$. nucleatum dose- and time-dependently regulates cell proliferationrelated genes and inhibits the proliferation of GFs.

3.3. F. nucleatum Promotes the Apoptosis of GFs. To further study the reason for the proliferation inhibition of GFs, the apoptosis rates of $F$. nucleatum-stimulated GFs were detected by flow cytometry. The results indicated that the low concentration of F. nucleatum (MOIs of 10) showed no influence on GF apoptosis, while high concentration of $F$. nucleatum (MOIs of 50, 100, 200, and 400) significantly decreased the number of normal cells and increased the number of apoptosis cells at $2 \mathrm{~h}$ stimulation and maintained the similar apoptosis trend to $36 \mathrm{~h}$. At MOIs of 50 and 100, the number of early apoptotic cells was greater than the number of late apoptotic cells at the $2,6,12,24$, and $36 \mathrm{~h}$ F. nucleatum stimulation, while at the MOIs of 200 and 400, the number of late apoptotic GFs was larger than the early apoptotic cells (Figure 3(a) and Supplementary Figure 4(a)). The DEGs of the 54 samples enriched in the apoptotic process (GO: 0006915) were compared using an overlap analysis, and the results suggested that $24,31,50,84$, and 97 apoptosisrelated genes were differentially expressed at $2 \mathrm{~h}, 6 \mathrm{~h}, 12 \mathrm{~h}$, $24 \mathrm{~h}$, and $48 \mathrm{~h}$, respectively (Figure $3(\mathrm{~b})$ ). Three apoptosisrelated genes, CSF2, PTGS2, and SOD2, were continuously upregulated across the 5 time points (Figure 3(b) and Supplementary Figure 4(b)). A trypan blue staining assay indicated that $F$. nucleatum dose-dependently increased the number of nonviable cells, which were stained blue, and the cell morphology changed from long spindle to round, and fewer live cells were detected after $F$. nucleatum stimulation at MOIs of 200 and 400 (Figure 3(c)). These results suggest that $F$. nucleatum might inhibit the proliferation of GFs by dose-dependently promoting GF apoptosis and timedependently upregulating a group of apoptosis processrelated genes. 

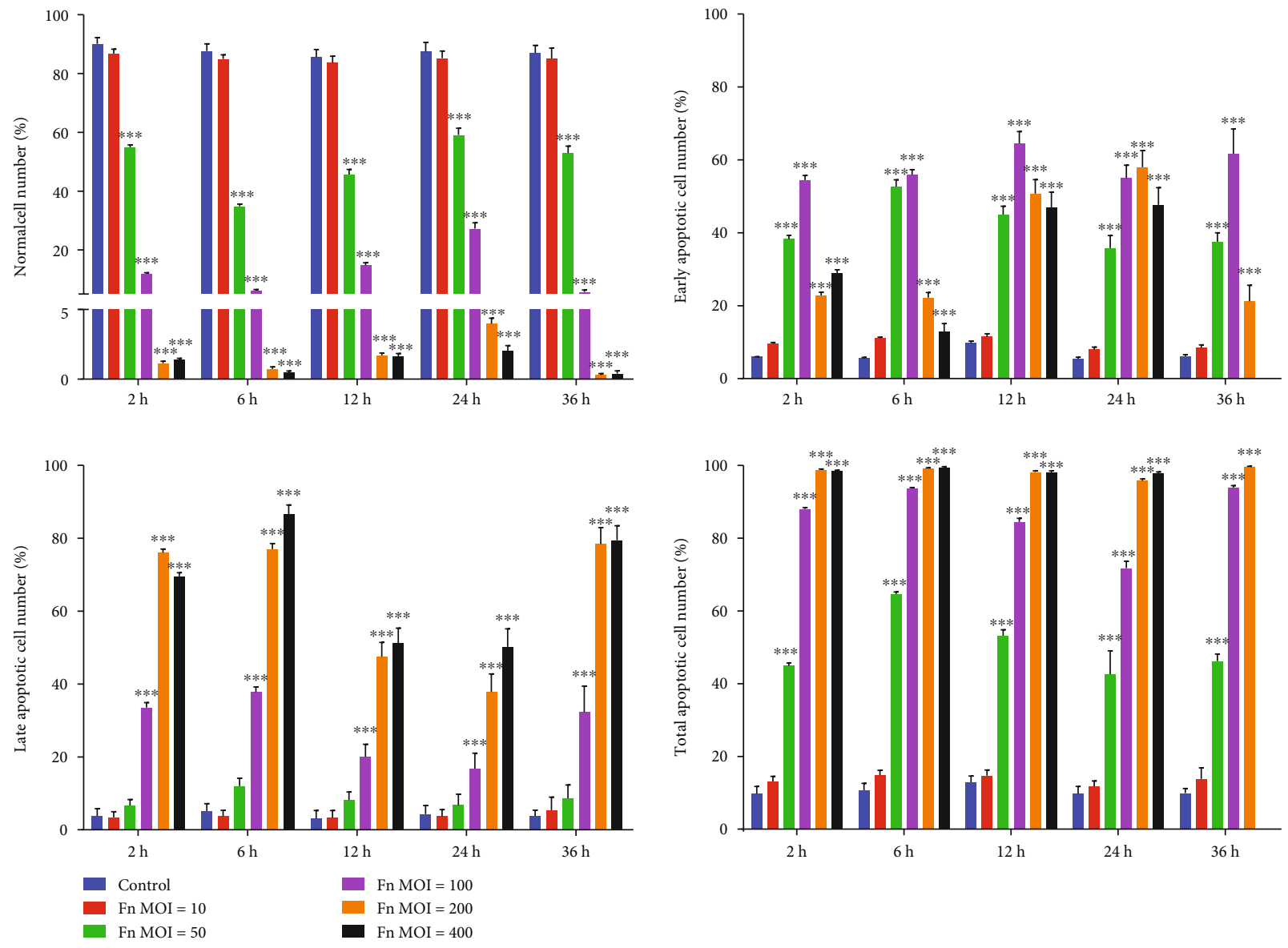

(a)
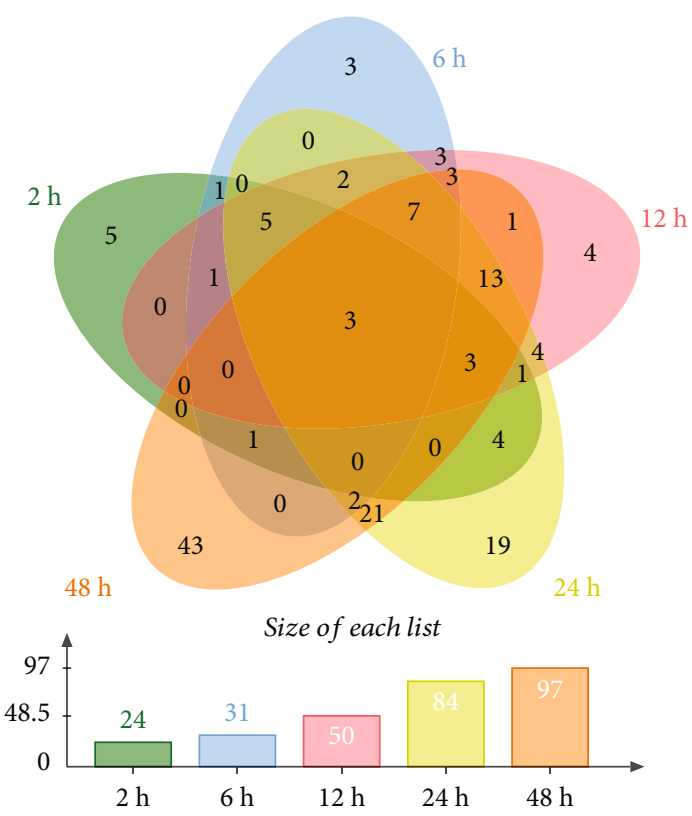

(b)

FIgure 3: Continued 
NC

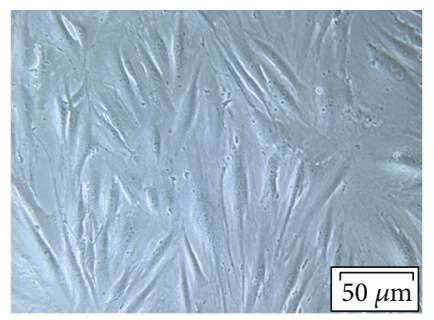

PC

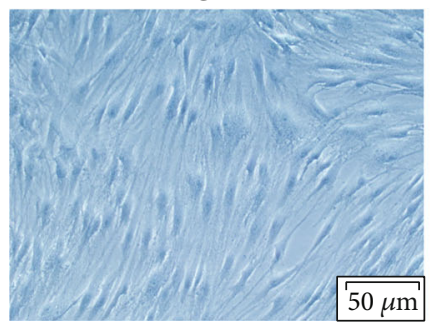

Fn MOI $=10$

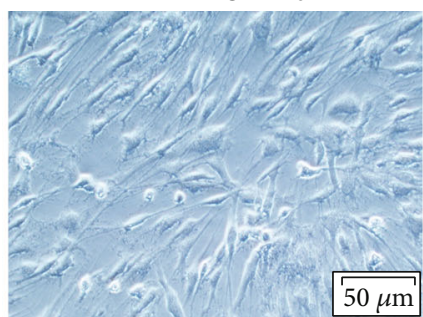

Fn MOI $=200$

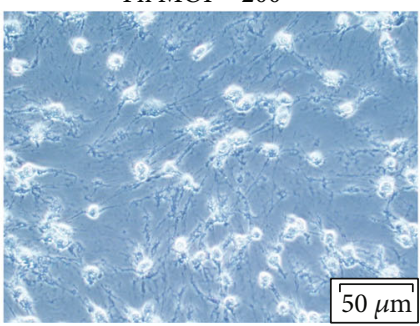

Fn MOI $=50$

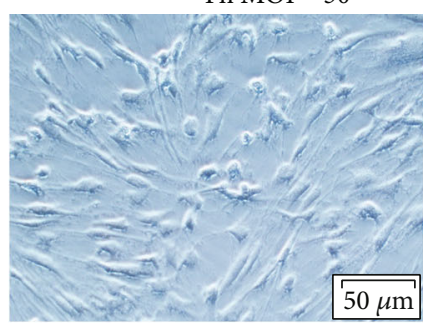

Fn MOI $=100$

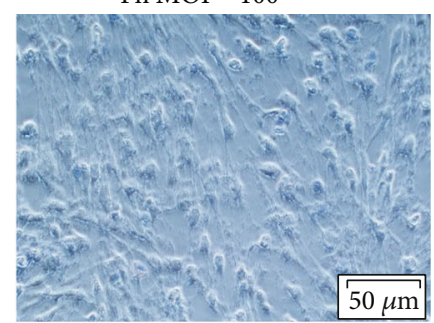

Fn MOI $=400$

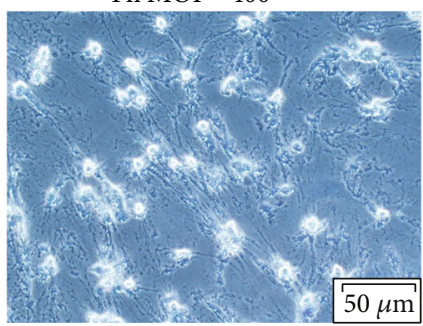

(c)

FIGURE 3: Effect of F. nucleatum on GF apoptosis. (a) Statistical analysis of GF apoptosis with F. nucleatum stimulation (MOIs of 0, 10, 50, $100,200$, and 400$)$ at $2 \mathrm{~h}, 6 \mathrm{~h}, 12 \mathrm{~h}, 24 \mathrm{~h}$, and $36 \mathrm{~h}$. The histogram represents the mean $\pm \mathrm{SD}(n=3)$. (b) Venn diagram of apoptosis-related DEGs from the GO biological process analysis of the five paired comparisons. (c) Trypan blue staining results of GFs without or with $F$. nucleatum stimulation at MOIs of 10, 50, 100, 200, and 400 at $24 \mathrm{~h}$. Scale bar: $50 \mu \mathrm{m}$. NC: negative control; PC: positive control. Statistical analyses were performed by two-way ANOVA with Turkey's multiple-comparison test. ${ }^{* * *} P<0.001$ compared with the control at each time point.

3.4. F. nucleatum Promotes Intracellular ROS Generation in GFs. To investigate whether the alteration in GF biological properties is associated with intracellular ROS production, GFs were treated with F. nucleatum (MOIs of 10, 50, 100, 200 , and 400) for $2,6,12,24,36$, and $48 \mathrm{~h}$, and the level of ROS was detected at the different stimulation times and doses. The flow cytometry analysis results showed that the level of intracellular ROS was significantly elevated in a doseand time-dependent manner (Figures 4(a) and 4(c)). The DEGs of the 54 samples enriched in the response to reactive oxygen species (GO: 0000302) were compared using an overlap analysis, and the results indicated that the number of differentially expressed ROS production-related genes also increased in a time-dependent manner, and 2, 4, 6, 16 , and 22 DEGs were detected after $F$. nucleatum stimulation (MOI of 100) at 2, 6, 12, 24, 36, and $48 \mathrm{~h}$ (Figure 4(b)). SOD2 is a unique DEG that was continuously upregulated across the 5 time points. The relative gene expression level of SOD2 is shown in Figure 4(d). In addition, SOD2 also acts as the main contributor to the regulation of the proliferation and apoptosis of GFs (Supplementary Figure 3 and Supplementary Figure 4(b)).

3.5. F. nucleatum Promotes GF Inflammatory Cytokine Production. The expression of Toll-like receptor- (TLR-) 2 and TLR4, which are closely related to inflammatory cytokine production, was analyzed by qRT-PCR. The expression of the TLR4 gene was elevated after F. nucleatum stimulation at $2 \mathrm{~h}, 12 \mathrm{~h}, 24 \mathrm{~h}$, and $36 \mathrm{~h}$, while showing no significant differences compared with the TLR4 expression in normal cells at $48 \mathrm{~h}$ (Figure 5(a)). The TLR2 gene expression level was increased in F. nucleatum-stimulated GFs at $2 \mathrm{~h}, 6 \mathrm{~h}$, and $12 \mathrm{~h}$, while showing no significant differences at $24 \mathrm{~h}$ and $48 \mathrm{~h}$ compared with that in nonstimulated GFs (Figure 5(d)). Compared with nonstimulated GFs at each time point, F. nucleatum-stimulated GFs showed significantly elevated gene expression levels of IL-6, IL-8, IL-1 $\beta$, and TNF- $\alpha$ across the whole time course (Figures 5(b), 5(e), $5(\mathrm{~h})$, and 5(j)); however, at the protein level, IL-6 and IL-8 were significantly increased after $F$. nucleatum stimulation, while IL- $1 \beta$ and TNF- $\alpha$ were not (Figures 5(c), 5(f), 5(i), and $5(\mathrm{k}))$. The DEGs of the 54 samples enriched in the defense response (GO: 0006952) were compared using an overlap analysis, which indicated that $31,43,47,73$, and 91 DEGs related to defense response were time-dependently increased after $F$. nucleatum stimulation; 14 overlapping DEGs were significantly upregulated among the 5 time points in the F. nucleatum stimulation groups (Figure $5(\mathrm{~g})$ and Supplementary Figure 5).

3.6. F. nucleatum Activates GF Nuclear Factor $-\kappa B$ (NF- $\kappa B)$, Mitogen-Activated Protein Kinase (MAPK), and Protein Kinase $B(A K T)$ Signaling Pathway. To further explore the mechanisms of $F$. nucleatum-induced biological process alteration in GFs, the cell proliferation, apoptosis, and immune response-related $\mathrm{NF}-\kappa \mathrm{B}, \mathrm{MAPK}$, and AKT signaling pathways were analyzed by western blotting and immunofluorescence. The results showed that $F$. nucleatum increased the proportion of p-p65 to p65 and $\mathrm{p}-\mathrm{I} \kappa \mathrm{B} \alpha$ to $\mathrm{I} \kappa \mathrm{B} \alpha$ after 5 min of stimulation and that this increase was maintained for $120 \mathrm{~min}$ (Figure 6(a)-6(c)). The immunofluorescence analysis of cells showed that p65 and p-p65 translocation from the cytoplasm to the nucleus also increased continuously after F. nucleatum stimulation from $5 \mathrm{~min}$ to $120 \mathrm{~min}$ (Figures 6(h) and 6(i)). These results indicate that F. nucleatum activates the NF- $\kappa \mathrm{B}$ signaling pathway by increasing the 

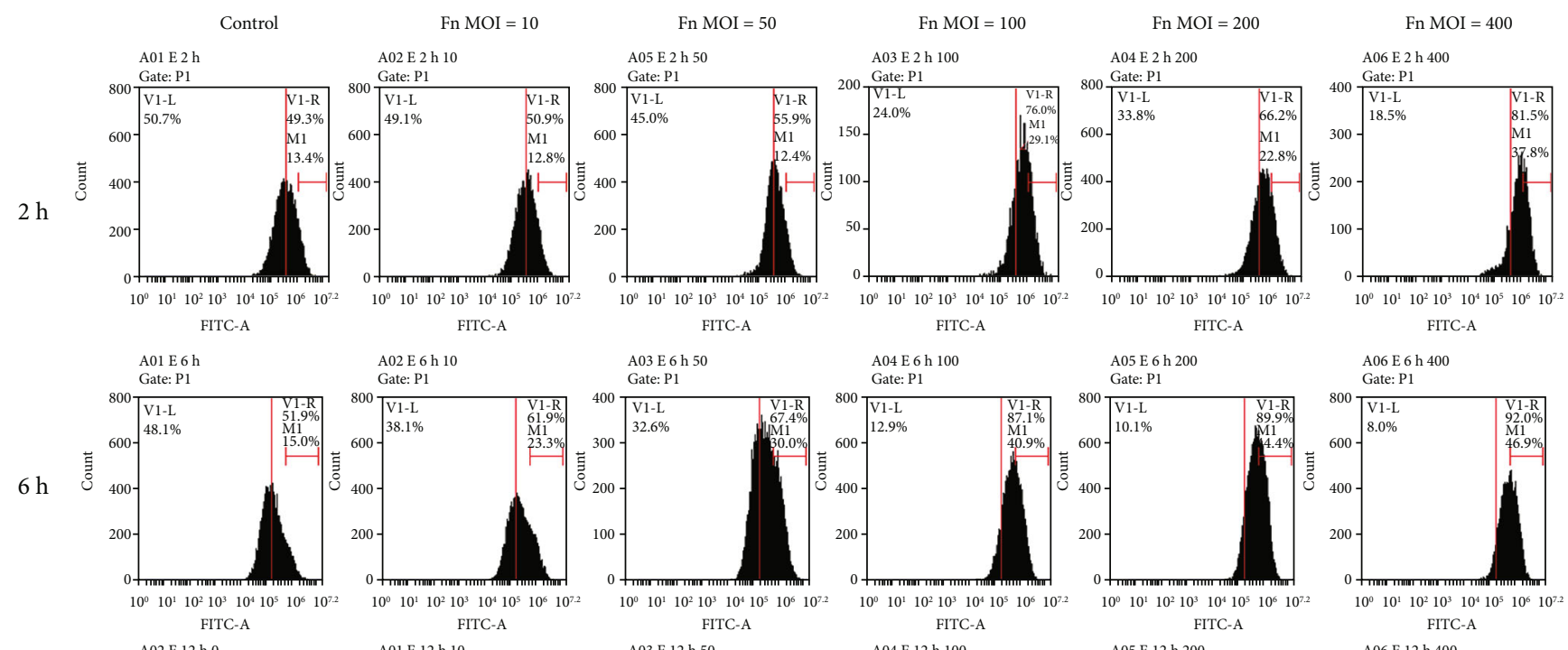

A05 E 6 h 200

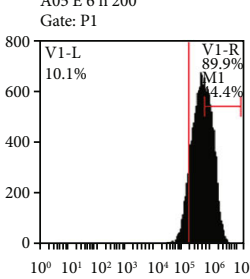

A06 E 6 h 400

Gate: P1

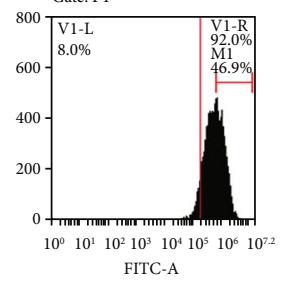

A02 E $12 \mathrm{~h}$

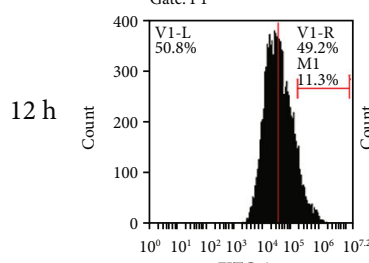

A01 E 12 h 10

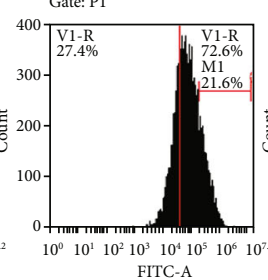

A03 E 12 h 50
Gate: Pl

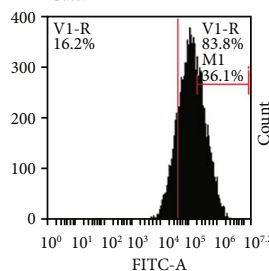

A04 E 12 h 100
Gate: P1

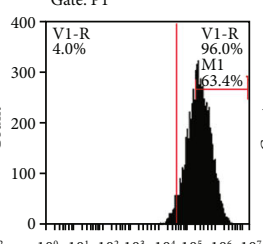

A05 E 12 h 200

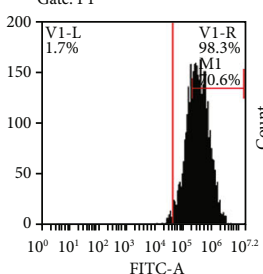

A06 E $12 \mathrm{~h} 400$

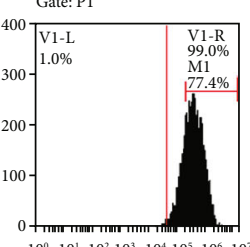

FITC-A

FITC-A
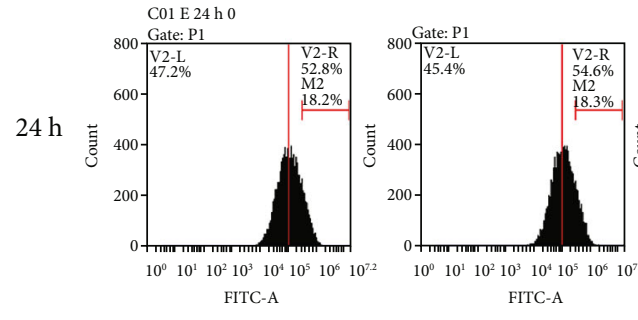

C03 E $24 \mathrm{~h} 50$

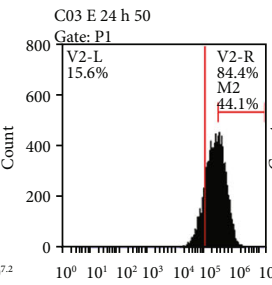

C04 E 12 h 100

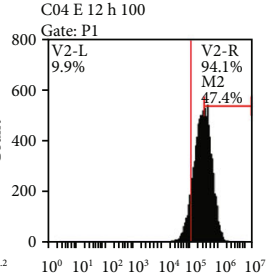

C04 E 24 h 200

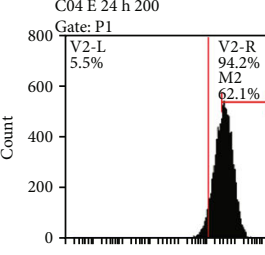

FITC-A

FITC-A

$10^{0} 10^{1} 10^{2} 10^{3} 10^{4} 10^{5} 10^{6} 10^{72}$

C05 E 24 h 400

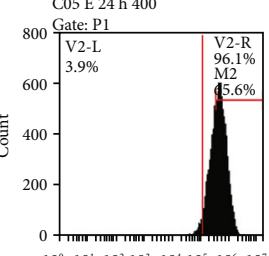

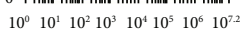
FITC-A
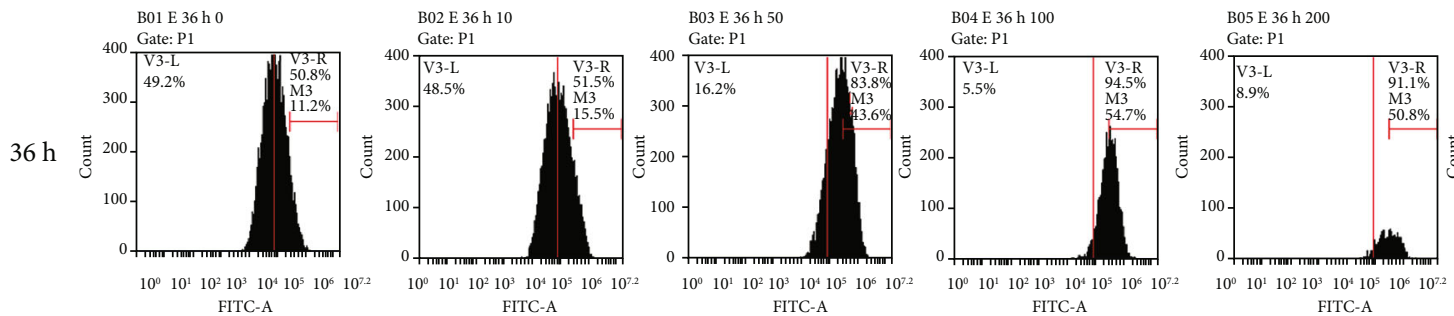

B06 E $36 \mathrm{~h} 400$
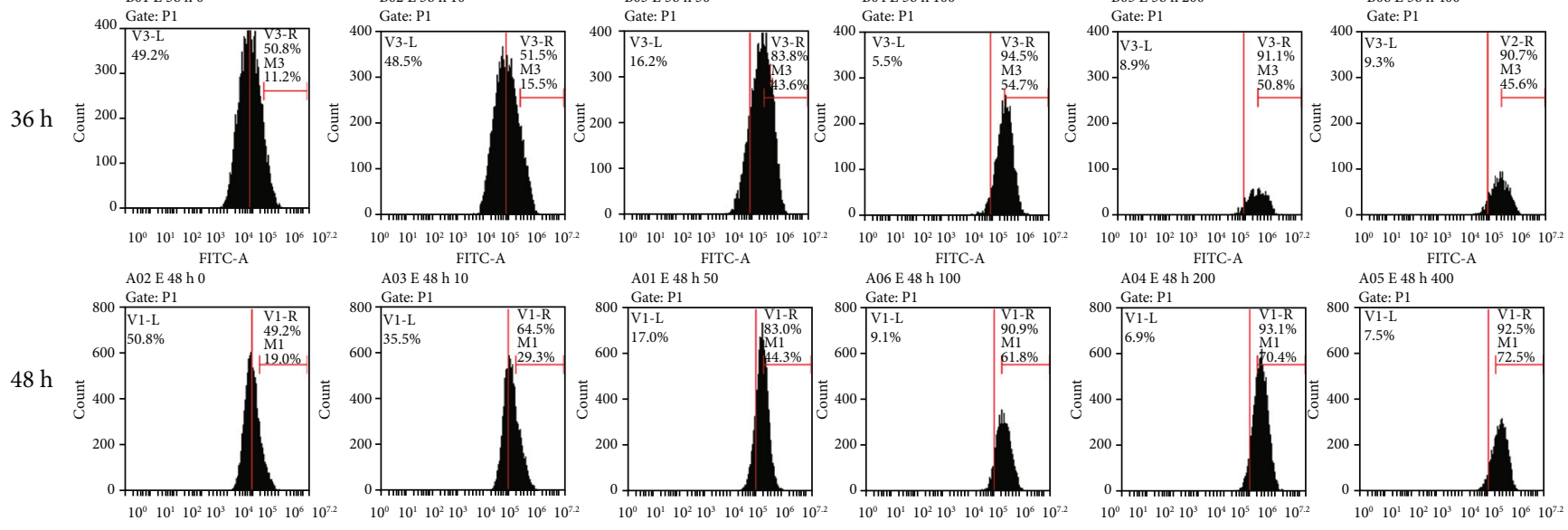

\begin{tabular}{l} 
A06 E 48 \\
800 Gate: P1 \\
\hline V1-L
\end{tabular}

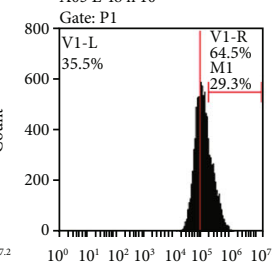

FITC-A

FITC-A

FITC-A
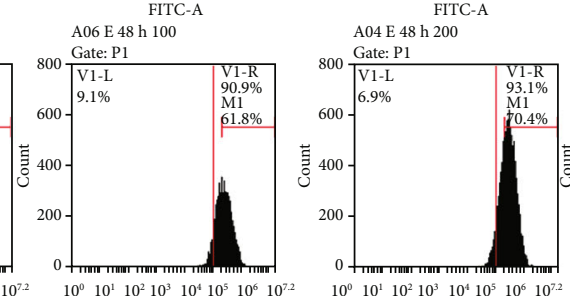

FITC-A
A05 E 48 h 400

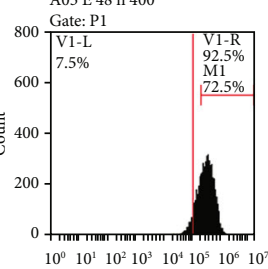

(a)

FIgURE 4: Continued. 

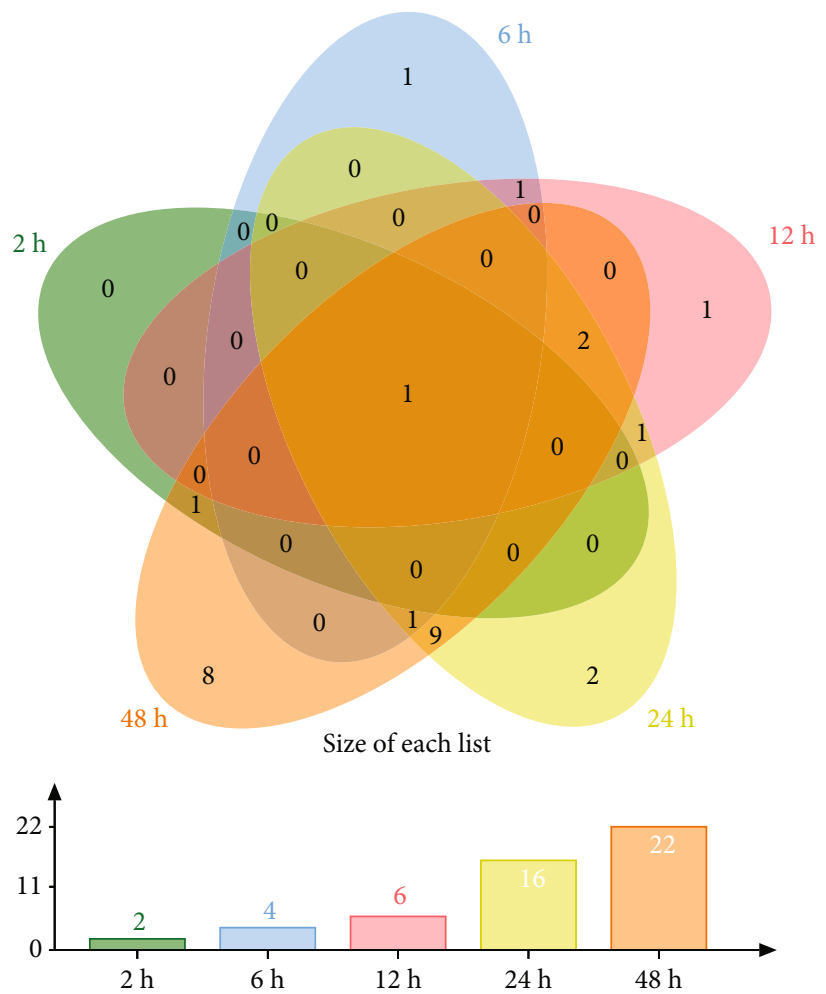

(b)

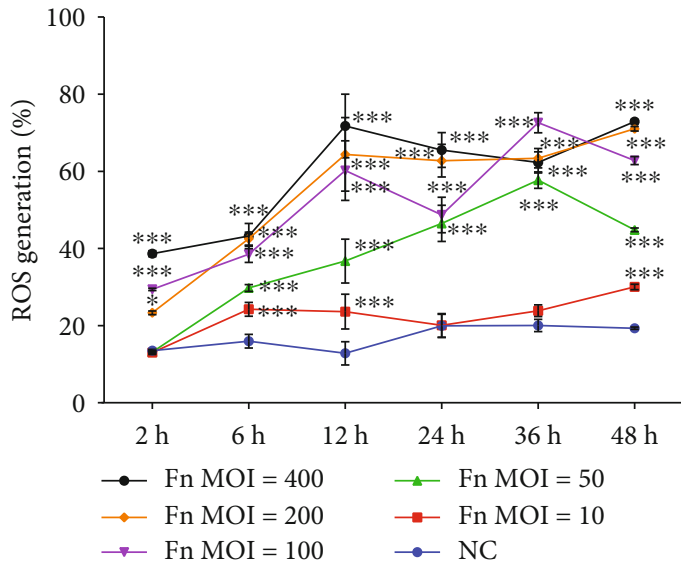

(c)

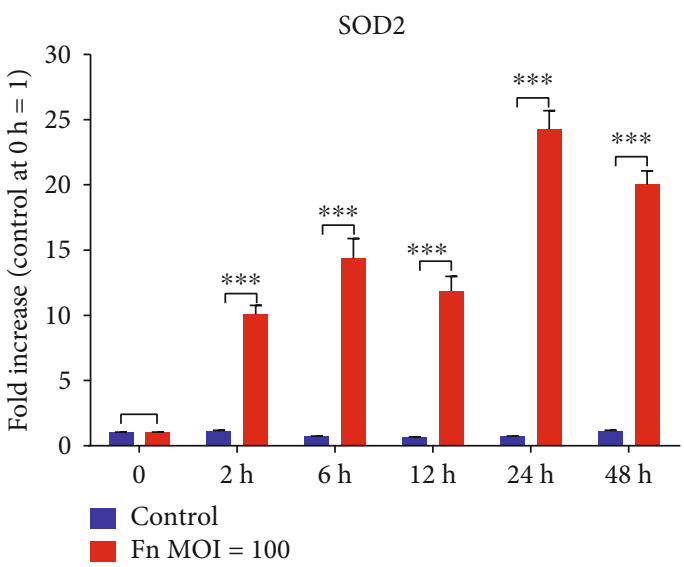

(d)

FIGURE 4: Effects of F. nucleatum on ROS generation in GFs. (a) Flow cytometry analysis of ROS production with $F$. nucleatum stimulation (MOIs of $0,10,50,100,200$, and 400 ) at $2 \mathrm{~h}, 6 \mathrm{~h}, 12 \mathrm{~h}, 24 \mathrm{~h}$, and $36 \mathrm{~h}$. (b) Venn diagram of ROS production-related DEGs from the GO biological process analysis after the five paired comparisons. (c) Statistical results of ROS generation by flow cytometry $(n=3)$. (d) The relative gene expression level of SOD2 by qRT-PCR. The histogram represents the mean \pm SD. Statistical analyses were performed by twoway ANOVA with Turkey's multiple-comparison test (c) and multiple $t$-test (d). ${ }^{*} P<0.05$ and ${ }^{* * *} P<0.001$ compared with the control at each time point.

phosphorylation levels of $\mathrm{p} 65$ and $\mathrm{I} \kappa \mathrm{B} \alpha$ and increasing the nuclear-to-cytoplasmic ratio of NF- $\kappa \mathrm{B}$ p65 and NF- $\kappa \mathrm{B}$ pp65 levels. Furthermore, we confirmed that $F$. nucleatum significantly activated AKT/MAPK signaling pathways by increasing the phosphorylation levels of AKT, ERK, JNK, and p38 (Figures 6(a) and 6(d)-6(g)). The protein expression ratio of $\mathrm{p}$-AKT/AKT and p-ERK/ERK was elevated after F. nucleatum stimulation at $5 \mathrm{~min}$ and maintained at a high level until 120 min (Figures 6(f) and 6(g)). In addition, the relative value of $\mathrm{p}$-JNK/JNK was increased after $30 \mathrm{~min}$ of $F$. nucleatum stimulation (Figure 6(d)), and the phosphorylation level of p38 was significantly increased after $5 \mathrm{~min}$ of stimulation with $F$. nucleatum (Figure 6(e)). Furthermore, the protein level of p53 and phosphorylated p53 was detected, and the results indicated that $F$. nucleatum could not increase the protein expression 
IL-6

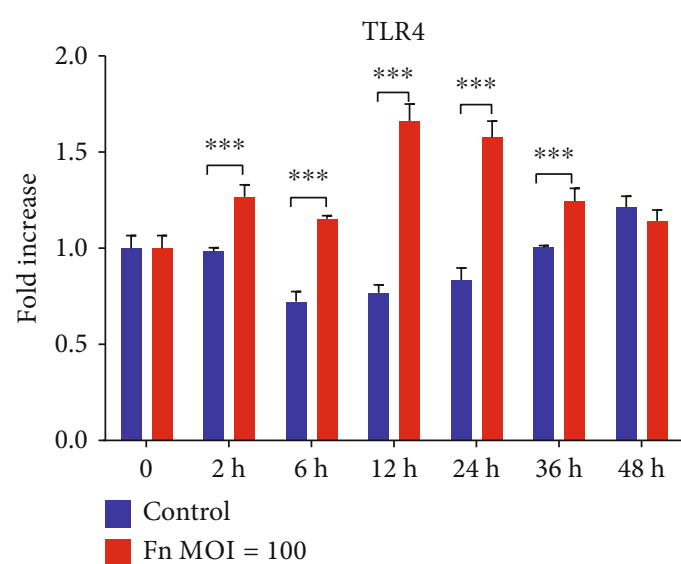

(a)

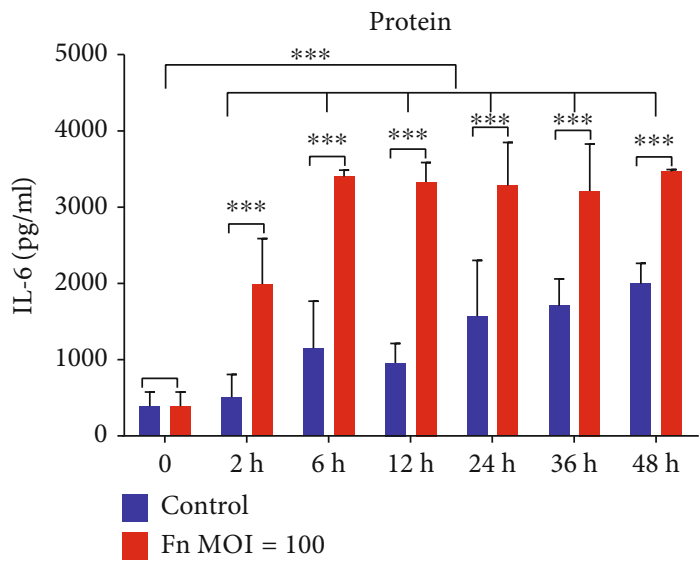

(c)

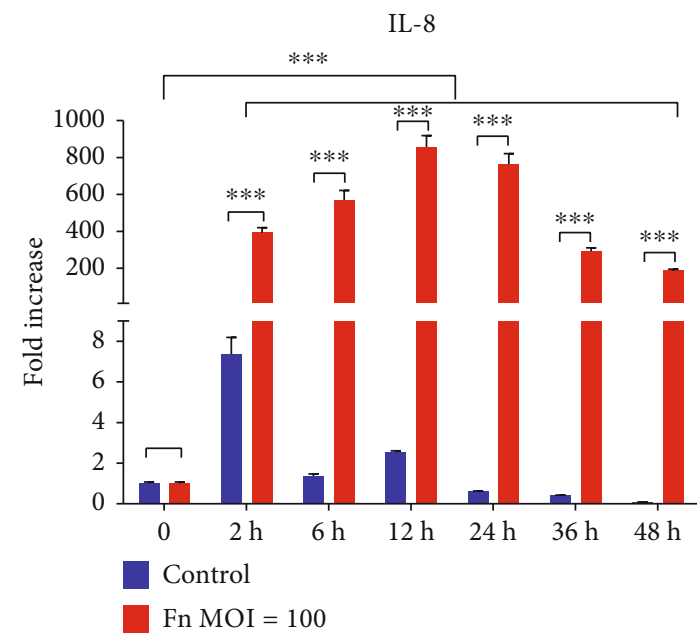

(e)

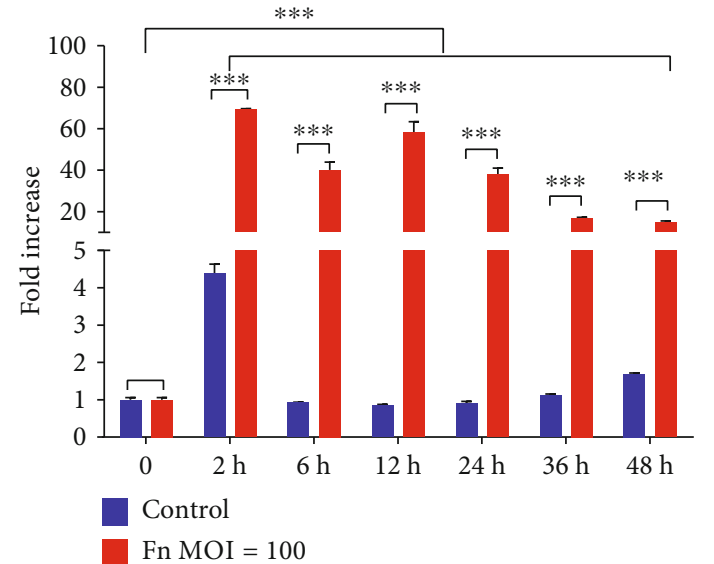

(b)

TLR2

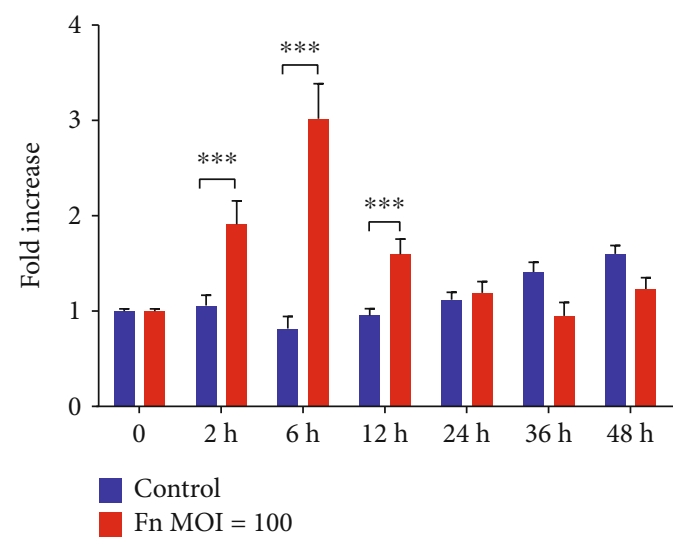

(d)

Protein

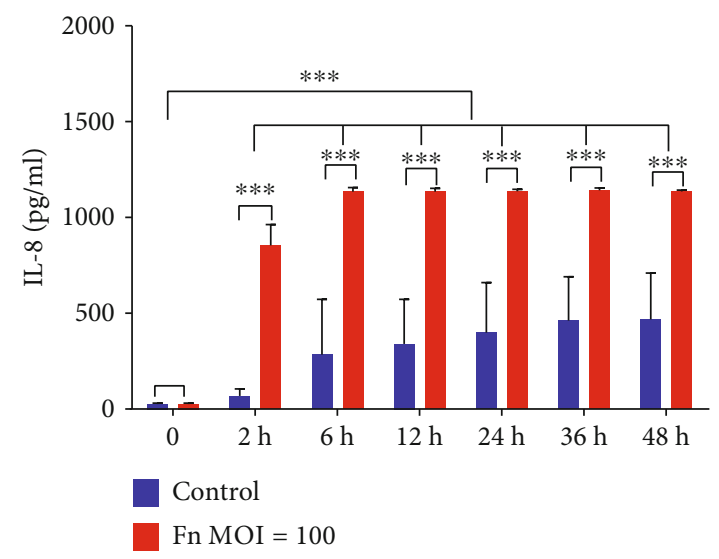

(f)

Figure 5: Continued. 

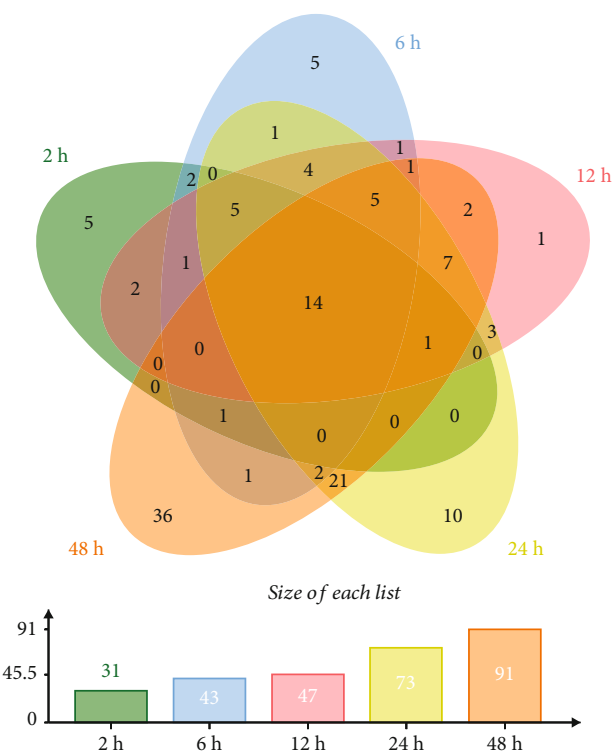

(g)

IL-1 $\beta$

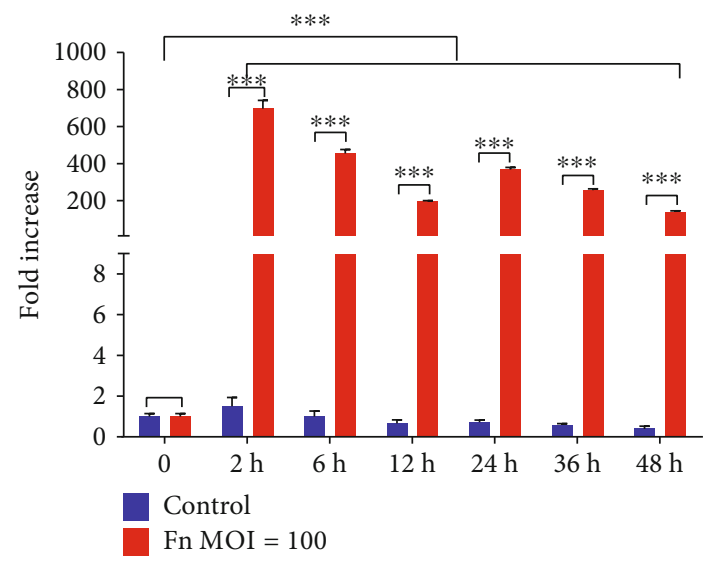

(h)

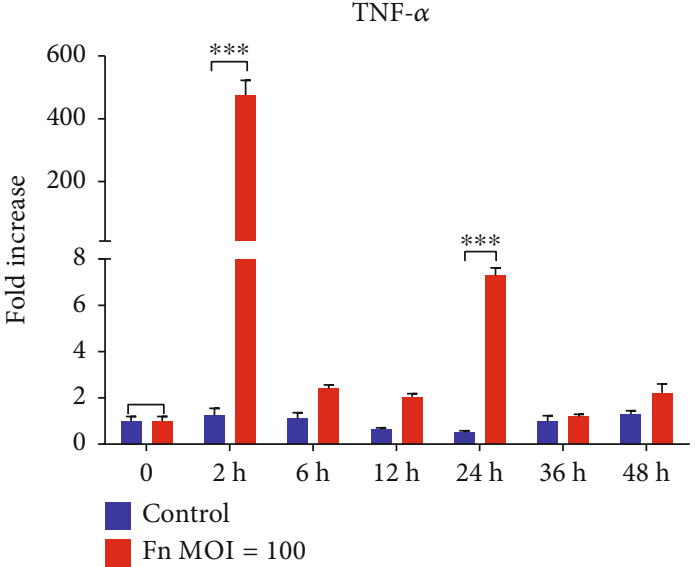

(j)

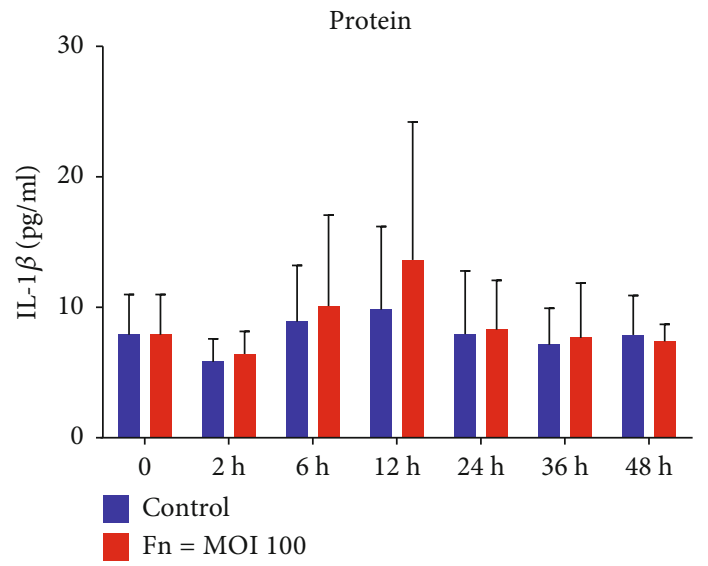

(i)

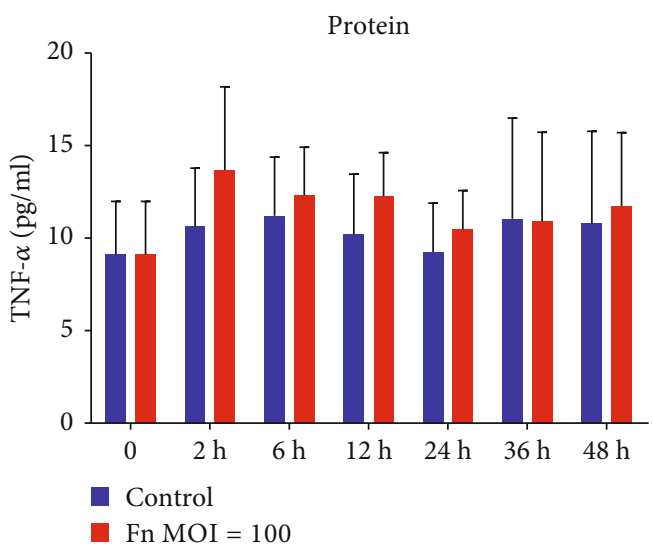

(k)

Figure 5: Effects of F. nucleatum on inflammatory cytokine production in GFs. TLR4 (a), TLR2 (d), IL-6 (b), IL-8 (e), IL-1 $\beta$ (h), and TNF- $\alpha$ (g) gene expression with F. nucleatum stimulation (MOIs of 0 and 100) from 0 to $48 \mathrm{~h}(n=3)$. IL-6 (c), IL-8 (f), IL- $1 \beta$ (i), and TNF- $\alpha$ (k) protein expression with F. nucleatum stimulation (MOIs of 0 and 100) from 0 to $48 \mathrm{~h}(n=3)$. (g) Venn diagram of the defense responserelated DEGs among the five time points. The histogram represents the mean \pm SD. Statistical analyses were performed by multiple $t$-test. ${ }^{*} P<0.05,{ }^{* *} P<0.01$, and ${ }^{* * *} P<0.001$. 


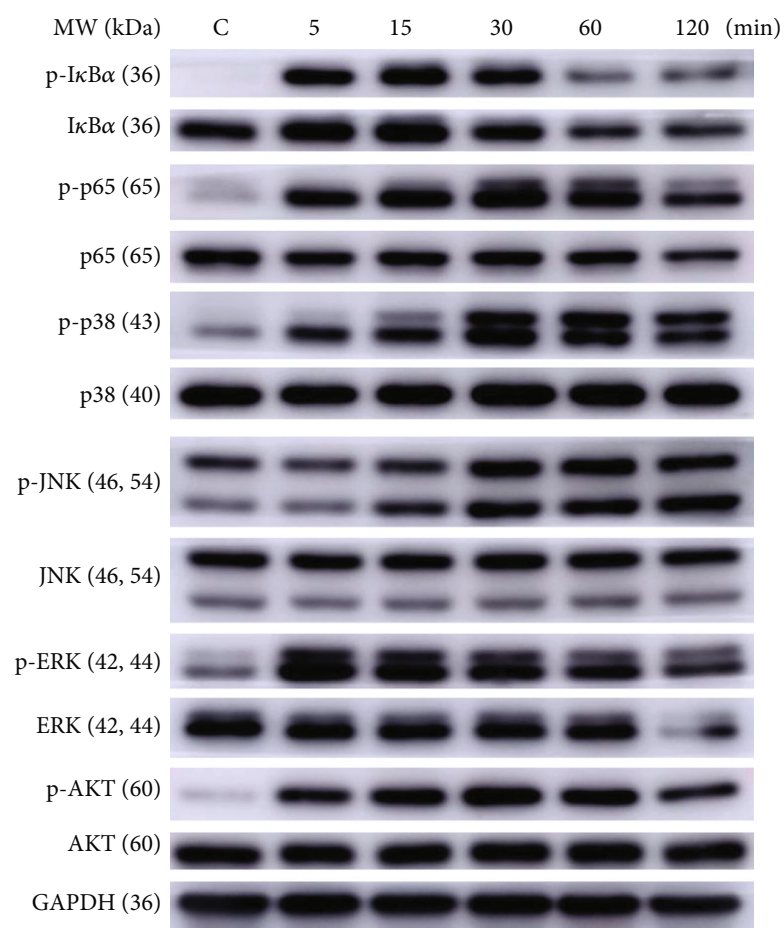

(a)

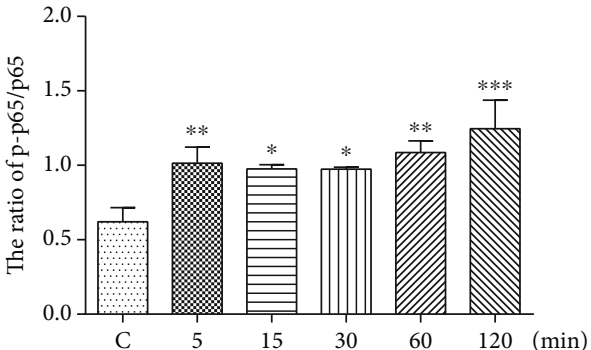

(b)

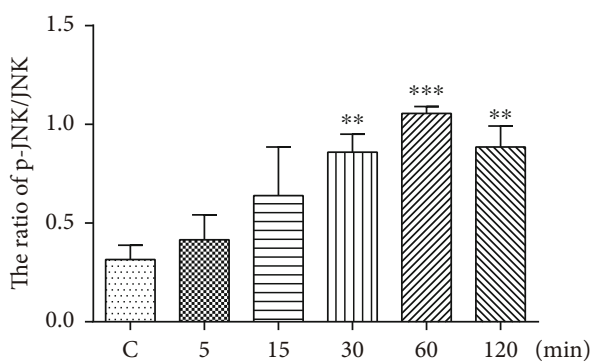

(d)

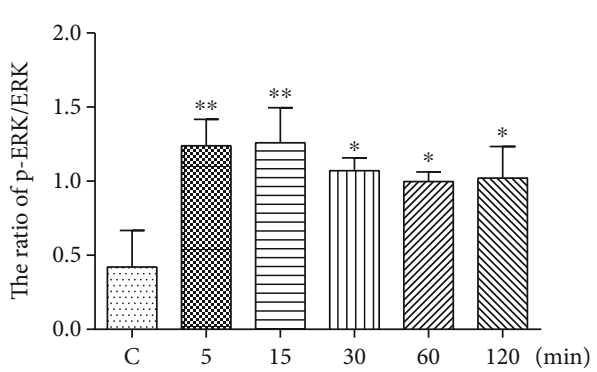

(f)

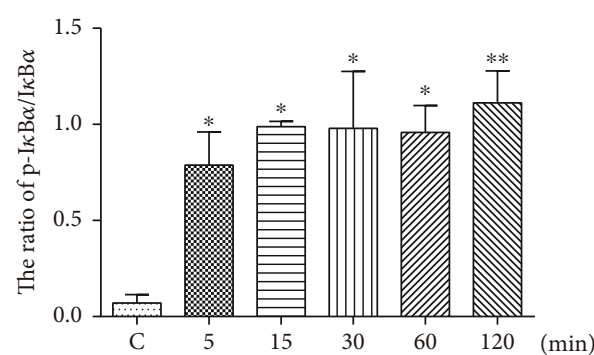

(c)

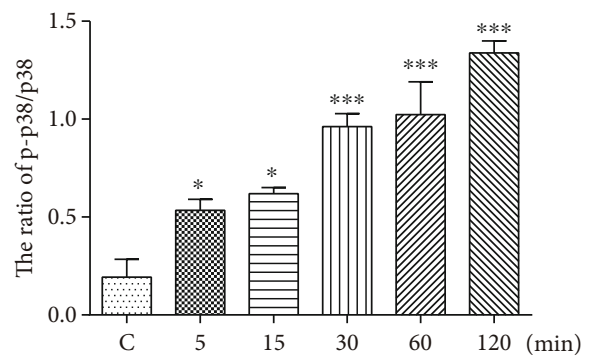

(e)

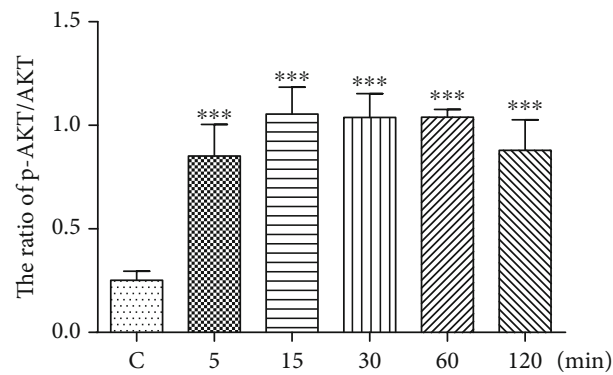

(g)

FIgURE 6: Continued. 


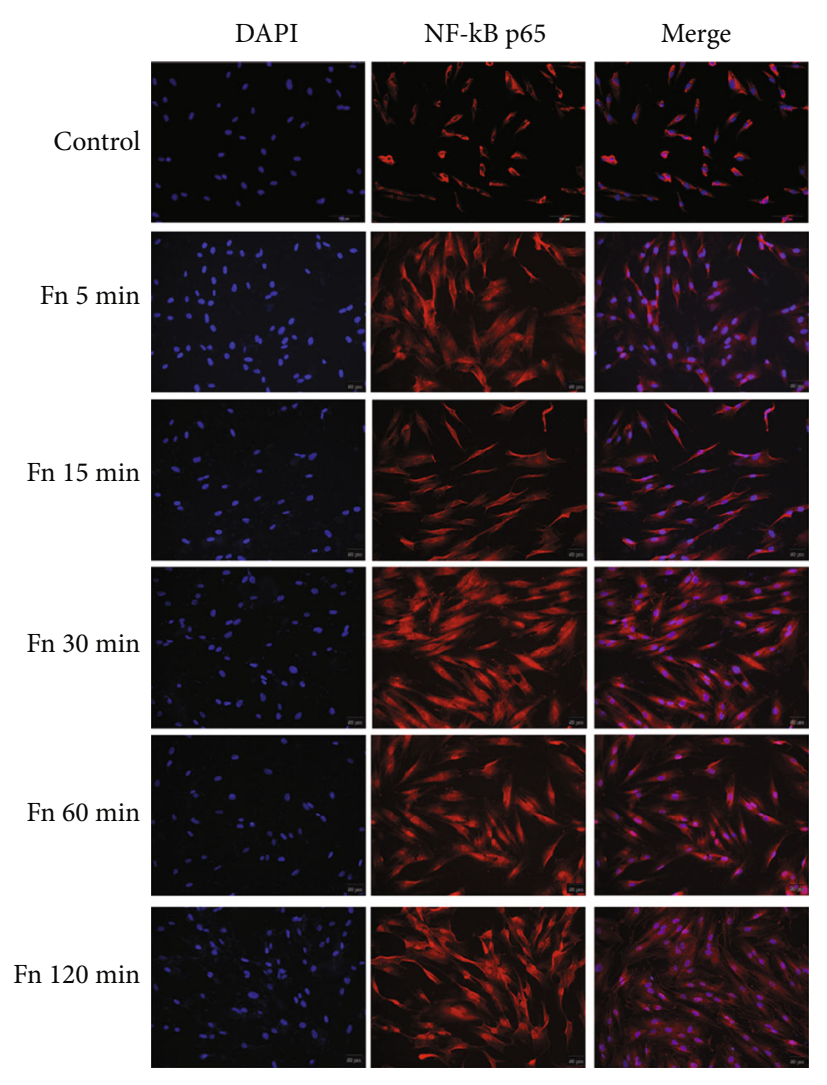

(h)

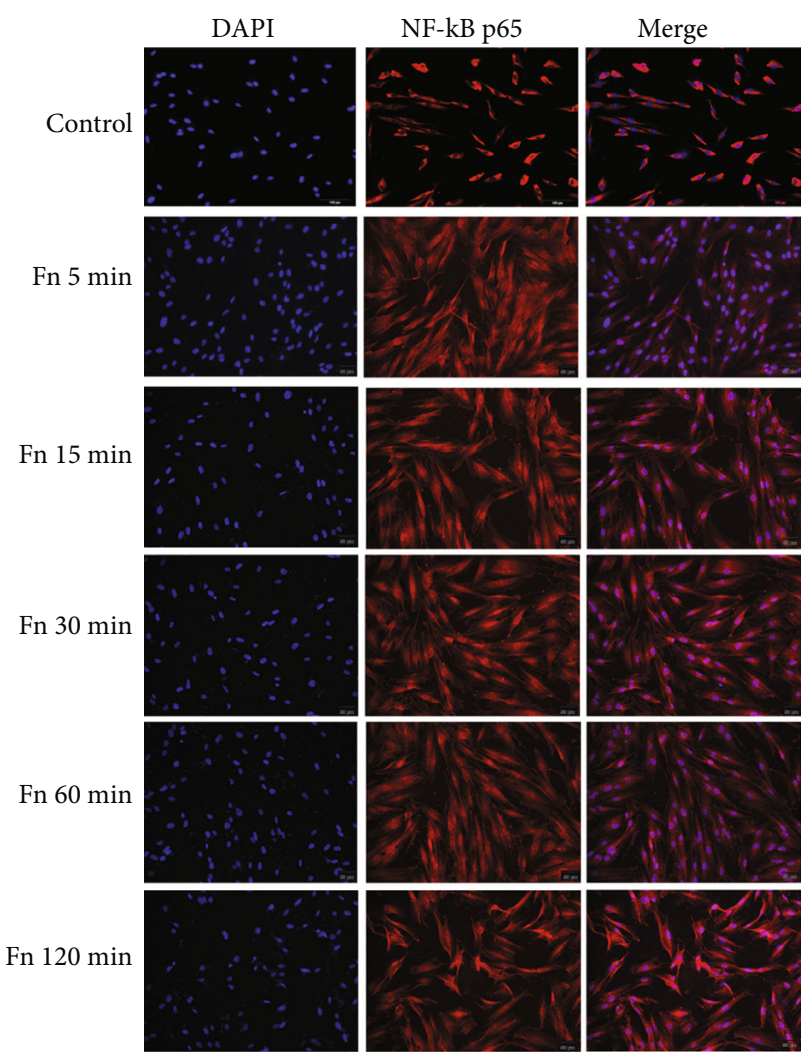

(i)

FIgURe 6: Effects of F. nucleatum on the activation of the NF- $\kappa \mathrm{B}$, MAPK, and PI3K-AKT pathways in GFs. (a) The protein levels of p38, phosphorylated p38, JNK, phosphorylated JNK, ERK, phosphorylated ERK, NF- $\kappa$ B p 65 , phosphorylated NF- $\kappa \mathrm{B}$ p 65 , I $\kappa \mathrm{B} \alpha$, phosphorylated $\mathrm{I} \kappa \mathrm{B} \alpha, \mathrm{AKT}$, and phosphorylated AKT were detected by western blotting. The relative level of phosphorylated NF- $\kappa \mathrm{B}$ p65/NF- $\kappa \mathrm{Bp} 65$ (b), phosphorylated $\mathrm{I} \kappa \mathrm{B} \alpha / \mathrm{I} \kappa \mathrm{B} \alpha$ (c), phosphorylated JNK/JNK (d), phosphorylated p38/p38 (e), phosphorylated ERK/ERK (f), and phosphorylated AKT/AKT $(\mathrm{g})$ was detected $(n=3)$. Immunofluorescence images of NF- $\kappa \mathrm{B}$ p65 (h) and phosphorylated NF- $\kappa$ B p65 (i) in cells. The histograms represent means \pm SD. Statistical analyses were performed using one-way ANOVA with Tukey's multiplecomparison test. ${ }^{*} P<0.05,{ }^{* *} P<0.01$, and ${ }^{* * *} P<0.001$ compared with the Control.

ratio of p-p53/p53 after stimulation for $5 \mathrm{~min}$ to $120 \mathrm{~min}$ (Supplementary Figure 6).

3.7. Whole-Transcriptome Analysis of $N F-\kappa B, M A P K$, and PI3K-AKT Signaling Pathways in F. nucleatum-Stimulated GFs. To further clarify the correlation among cell proliferation, apoptosis, oxidative stress, cytokine production and AKT/MAPK, and NF- $\kappa$ B signaling pathways, the DEGs induced by $F$. nucleatum stimulation from the 54 samples at each time point were integrated and visualized by Pathview. The results indicated that the DEGs were significantly enriched in the NF- $\kappa \mathrm{B}, \mathrm{PI} 3 \mathrm{~K}-\mathrm{AKT}$, and MAPK signaling pathways, which suggest that these pathways are significantly activated by $F$. nucleatum stimulation at the gene expression level and are consistent with the results of our biological experiments (Figure 7, Supplementary Figure 7 and Supplementary Figure 8 ). For the NF- $\kappa \mathrm{B}$ signaling pathway, we confirmed that most DEGs downstream of the $\mathrm{NF}-\kappa \mathrm{B}$ signaling pathway were significantly upregulated by F. nucleatum stimulation, which is critical in regulating cell proliferation, apoptosis, ROS generation, and cytokine production (Figure 7). For example, cIAP1/2 and TRAF1/2 were elevated after $F$. nucleatum stimulation at $2 \mathrm{~h}$, and
Bcl-2 was upregulated at $12 \mathrm{~h}$ after $F$. nucleatum stimulation; these genes play key roles in cell proliferation and apoptosis. The gene expression levels of IL-8, cyclooxygenase 2 (COX2), $\mathrm{A} 20, \mathrm{I} \kappa \mathrm{B} \alpha$, and MIP2 were significantly upregulated throughout the whole F. nucleatum stimulation (from 2 to $48 \mathrm{~h}$ ); these genes are closely associated with GF intracellular ROS generation and inflammatory cytokine production (Figure 7 and Supplementary Figure 9). In addition, we found that a large number of $F$. nucleatum-stimulated DEGs were enriched in the PI3K-AKT signaling pathway (Supplementary Figure 7) and MAPK signaling pathways (Supplementary Figure 8), which are mainly involved in cell proliferation and apoptosis. Furthermore, we found that the PI3K-AKT and MAPK signaling pathways were upstream of the NF- $\kappa$ B signaling pathway, which plays a synergetic role in regulating cell proliferation, apoptosis, ROS generation, and the inflammatory response.

\section{Discussion}

Characterized by gingival inflammation and periodontal supporting tissue destruction, periodontitis is prevalent among adults over 30 years old [44, 45]. Understanding 


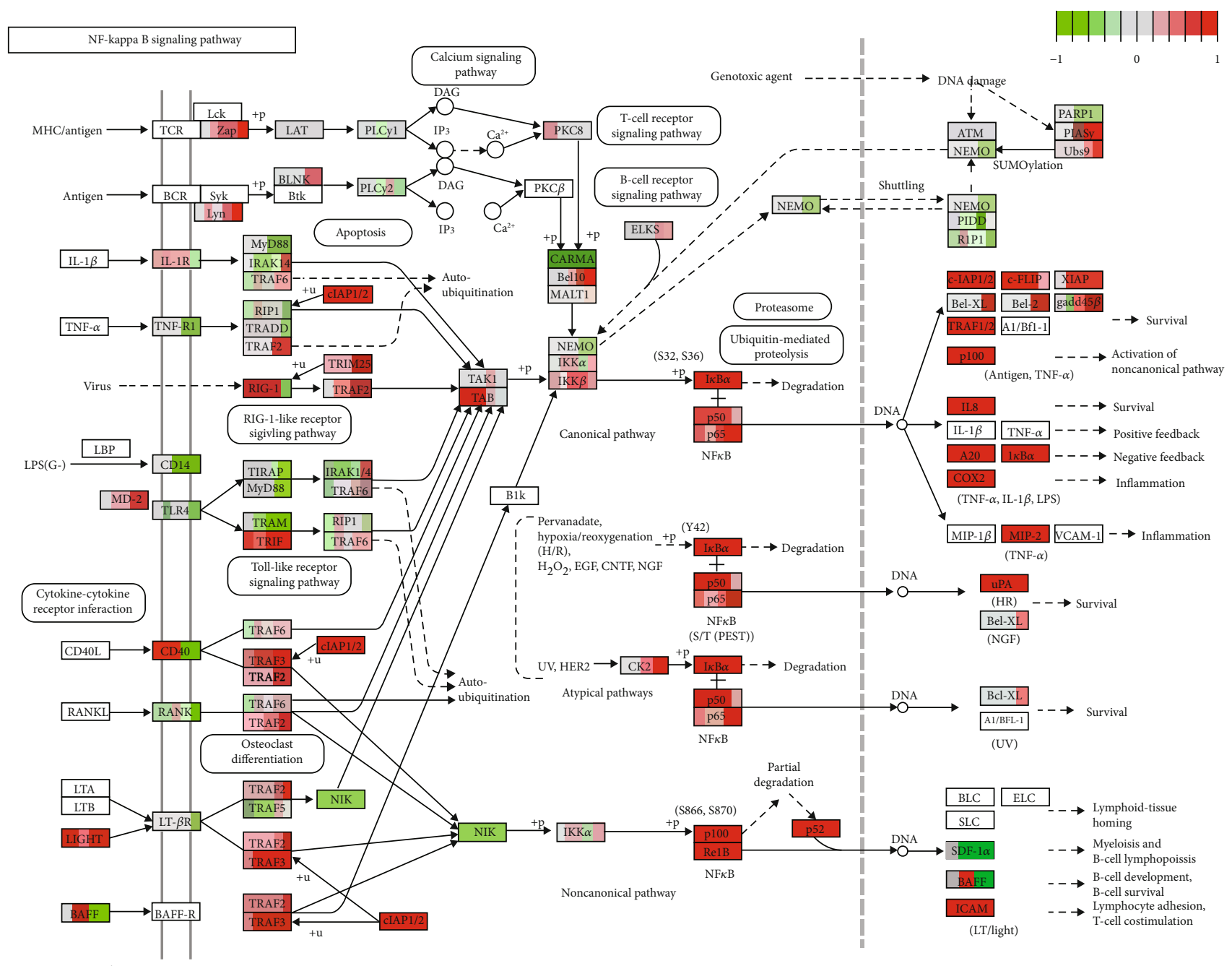

Data on KEGG graph

Rendered by Pathview

Figure 7: The Pathview analysis of the NF- $\kappa \mathrm{B}$ signaling pathway. Every box is divided into five parts on average, and each part represents the relative gene expression level of F. nucleatum-stimulated GFs at $2 \mathrm{~h}, 6 \mathrm{~h}, 12 \mathrm{~h}, 24 \mathrm{~h}$, and $48 \mathrm{~h}$ from left to right. The red color indicates that the gene expression level is upregulated after F. nucleatum stimulation. The green color indicates that the gene level is downregulated after $F$. nucleatum stimulation. The white color indicates that the gene expression level is not influenced by F. nucleatum stimulation. The gene expression level is calculated by the log fold change in the F. nucleatum stimulation group relative to the control group at each time point.

the pathogenic mechanisms of oral pathogens in periodontitis and identifying risk factors are important for maintaining human periodontal health. Previous studies have provided in-depth insights into the pathogenic effects of P. gingivalis [46]. F. nucleatum often appears simultaneously with $P$. gingivalis at periodontal infection sites [47], while its pathogenic role in periodontal disease has not been comprehensively reported. This study is the first to illuminate the comprehensive effects of F. nucleatum on cell proliferation, apoptosis, ROS generation, and inflammatory cytokine production in GFs.

Our study confirms that F. nucleatum inhibits the proliferation and promotes the apoptosis of GFs, which is in contrast to the role $F$. nucleatum plays in colorectal cancer cell (CRC) proliferation. F. nucleatum has been reported to promote E-cadherin-expressing CRC proliferation by modulating the E-cadherin/ $\beta$-catenin signaling pathway or activating TLR4 signaling to NF- $\kappa \mathrm{B}$ and upregulating the expression of microRNA-21 [24, 48]. Our transcriptomic analysis demonstrates that F. nucleatum alters the expression of proapoptotic genes in GFs by upregulating TRAILR2, NOXA, and PUMA expression and downregulating the substrates $\alpha$-tubulin, actin, fodrin, and PARP (Supplementary Figure 10), which are crucial for the regulation of cell proliferation and apoptosis [49-55]. We corroborated the gene expression levels of TRAILR2, NOXA, PUMA, $\alpha$-tubulin, actin, fodrin, and PARP by qRT-PCR, and the results indicated that F. nucleatum significantly upregulated TRAILR2 and NOXA at 2 to $48 \mathrm{~h}$, while increased PUMA gene expression at 2, 24, and $48 \mathrm{~h}$; F. nucleatum downregulated $\alpha$-tubulin, actin, fodrin, and PARP gene expression at the long time stimulation at $12 \mathrm{~h}$, $24 \mathrm{~h}$, and $48 \mathrm{~h}$, which were consistent with those of the RNA-seq analysis. However, at the $2 \mathrm{~h}$ and $6 \mathrm{~h}$ F. nucleatum stimulation, some disagreements between qRT-PCR and RNA-seq analysis were discovered in evaluating the gene 


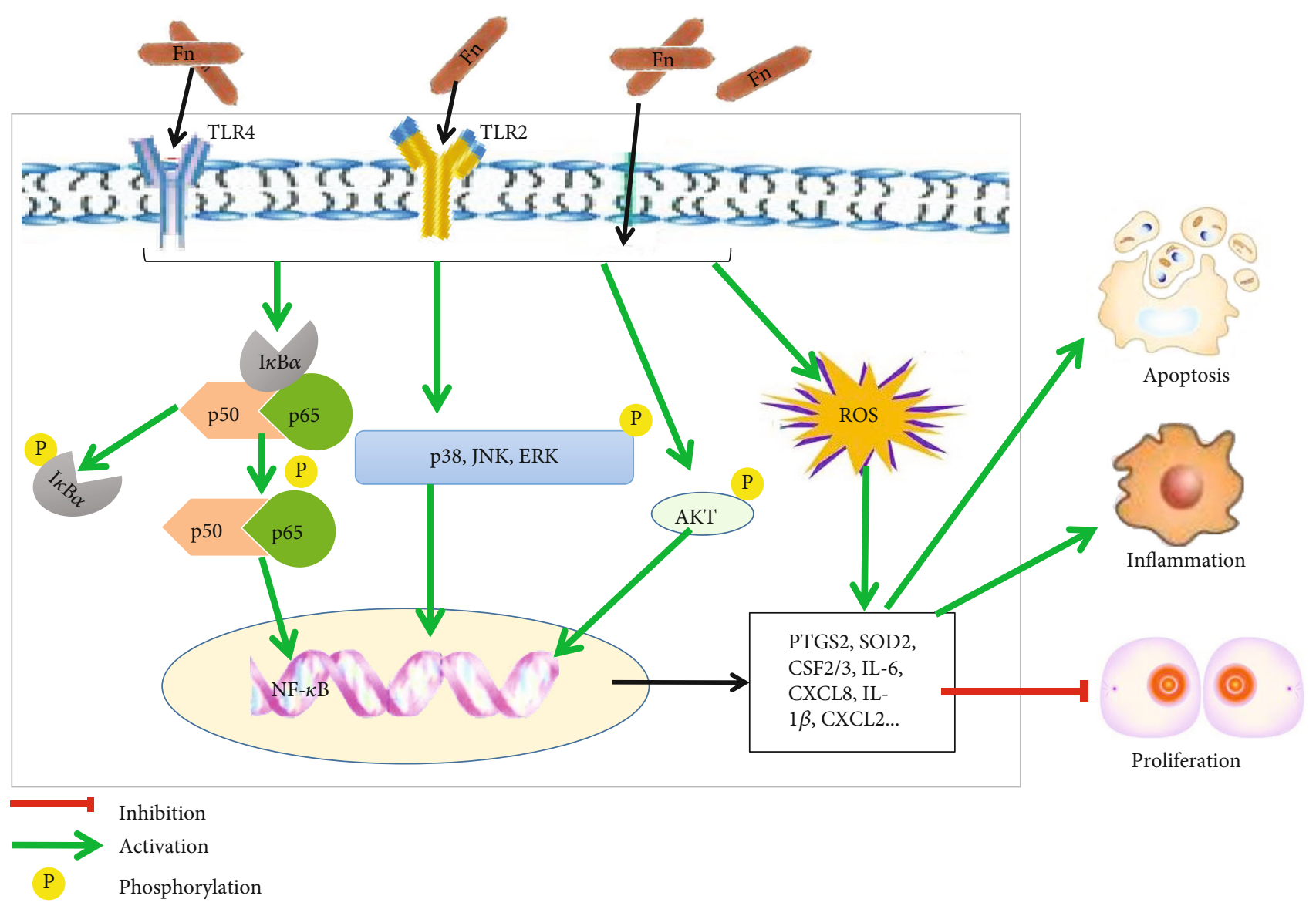

Figure 8: Putative mechanism for the effects of F. nucleatum on the biological processes in GFs. Schematic diagram depicting how F. nucleatum activates NF- $\kappa \mathrm{B}, \mathrm{MAPK}$, and AKT signaling pathways and induces cell proliferation, apoptosis, and inflammatory response. TLR4: Toll-like receptor 4; TLR2: Toll-like receptor 2; I $\kappa \mathrm{B} \alpha$ : inhibitors of NF- $\kappa \mathrm{B}$; AKT/PKB: protein kinase B; NF- $\kappa \mathrm{B}$ : nuclear factor kappa B; MAPK: mitogen-activated protein kinase; JNK: c-Jun N-terminal kinase; ERK: extracellular signal-regulated kinase.

level of actin and fodrin (Supplementary Figure 11). Moreover, F. nucleatum elevated the expression of Mcl-1, which ultimately induced apoptosis through bim-mediated mitochondrial apoptotic events (Supplementary Figure 10). F. nucleatum differentially regulates cell proliferation in GFs and CRCs, which indicates that the alteration of biological properties by $F$. nucleatum in normal human cells is quite different from that in tumor cell lines.

It has been reported that F. nucleatum stimulates ROS production and induces the tissue inflammatory response in TLR4-competent macrophages [56]. F. nucleatum induces IL- 8 , IL- $1 \beta$, TNF- $\alpha$, and ROS generation in Caco- 2 colorectal adenocarcinoma cells by impairing autophagic flux [35]. In addition, recent studies have reported that in GFs, two NADPH oxidase isoforms, NOX1 and NOX2, are activated in response to $F$. nucleatum infection $[57,58]$. However, the current study lacks the mechanism of ROS and inflammatory cytokine production in GFs after F. nucleatum stimulation. In this study, we confirm that F. nucleatum increases the production of ROS, activates TLR2 and TLR4 gene expression at early stimulation time points, and promotes the release of proinflammatory cytokines, such as IL-6 and IL-8 in GFs, which are concordant with the previous study. In addition, we found that $F$. nucleatum elevated the gene expression levels of IL- $1 \beta$ and TNF- $\alpha$, but not the protein level. In gingival epithelial cells (GECs), F. nucleatum has been shown to activate the NLRP inflammasome and promote IL- $1 \beta$ secretion, which is different from our results in GFs $[59,60]$. F. nucleatum differentially regulates IL-1 $\beta$ production in GFs and GECs, which indicates that the pathogenic mechanism of F. nucleatum in oral cells is quite complex, and it is necessary to clarify the mechanism of $F$. nucleatum in GFs.

Our genome-wide transcriptome analysis showed that $F$. nucleatum activates the NF- $\kappa \mathrm{B}, \mathrm{MAPK}$, and PI3KAKT signaling pathways, which is consistent with our biological validation results through western blotting assays and immunofluorescence. In addition, we demonstrated that a large number of DEGs are enriched in the MAPK signaling pathway and that the JNK and p38 MAPK signaling pathways are upstream of the NF- $\kappa \mathrm{B}$ signaling pathway, which plays a key role in regulating cell proliferation, apoptosis, and inflammatory response [61-63]. The ERK MAPK and PI3K-AKT signaling pathways are significantly activated in GFs, and the expression levels of proliferation-related genes, such as Myc and Bcl-2, are dramatically varied after $F$. nucleatum stimulation, which are crucial in deciding the cell survival [64-67]. 
According to the Pathview analysis, we found that a larger number of DEGs that were induced by F. nucleatum stimulation downstream of NF- $\kappa \mathrm{B}$ and AKT/MAPK signaling pathways (Figure 7 and Supplementary Figures 7, 8) are associated with cell proliferation, apoptosis, ROS generation, and production of inflammatory cytokines, such as bcl2, IL-8, COX2, JNK, and Mcl-1. We validated DEGs including COX2, IL- 8 , and bcl 2 by qRT-PCR, and the results were consistent with those of the RNA-seq analysis. IL-8 is an important chemokine and plays key roles in the acute inflammatory response and various inflammatory diseases [68, 69]. COX2 is critical for the formation of prostaglandins and maintains ROS homeostasis under inflammatory conditions, which are pivotal in the pathogenesis of periodontitis $[70,71]$. In the future, we will construct some gene knockout strains of F. nucleatum to further explore the mechanism of F. nucleatum in GFs.

\section{Conclusions}

Our study indicates that $F$. nucleatum alters the gene expression profiles of GFs in a time-dependent manner and plays multidimensional roles in regulating GF biological properties. F. nucleatum inhibits cell proliferation and facilitates cell apoptosis, ROS generation, and inflammatory cytokine production partly through the activation of AKT/MAPK and the NF- $\kappa \mathrm{B}$ signaling pathways in GFs. Our study opens a new window for understanding the pathogenic effects of periodontal pathogens on the host oral system. A schematic diagram of the effects of F. nucleatum on GFs and the potential pathogenic mechanism is shown in Figure 8.

\section{Abbreviations}

$\begin{array}{ll}\text { F. nucleatum: } & \text { Fusobacterium nucleatum } \\ \text { GFs: } & \text { Gingival fibroblasts } \\ \text { ROS: } & \text { Reactive oxygen species } \\ \text { IL: } & \text { Interleukin } \\ \text { TNF: } & \text { Tumor necrosis factor } \\ \text { DMEM: } & \text { Dulbecco's modified Eagle's medium } \\ \text { FBS: } & \text { Fetal bovine serum } \\ \text { RNA-seq: } & \text { RNA sequencing } \\ \text { QC: } & \text { Quality control } \\ \text { DEGs: } & \text { Differentially expressed genes } \\ \text { GO: } & \text { Gene ontology } \\ \text { KEGG: } & \text { Kyoto Encyclopedia of Genes and Genomes } \\ \text { PCA: } & \text { Principal component analysis } \\ \text { PBS: } & \text { Phosphate-buffered saline } \\ \text { MOI: } & \text { Multiplicity of infection } \\ \text { EdU: } & \text { 5-Ethynyl-2' }{ }^{\prime} \text {-deoxyuridine } \\ \text { DCFH-DA: } & 2^{\prime} \text { 7 }^{\prime} \text {-dichlorofluorescein diacetate } \\ \text { qRT-PCR: } & \text { Quantitative real-time polymerase chain } \\ & \text { reaction } \\ \text { ELISA: } & \text { Enzyme-linked immunosorbent assay } \\ \text { BCA: } & \text { Bicinchoninic acid } \\ \text { SDS-PAGE: } & \text { Sulfate-polyacrylamide gel electrophoresis } \\ \text { PVDF: } & \text { Polyvinylidene fluoride } \\ \text { DAPI: } & \text { 2-(4-Amidinophenyl)-6-indolecarbamidine } \\ & \text { dihydrochloride }\end{array}$

$\begin{array}{ll}\text { SD: } & \text { Standard deviation } \\ \text { ANOVA: } & \text { Analysis of variance } \\ \text { TLRs: } & \text { Toll-like receptors } \\ \text { NF- } \kappa \text { B: } & \text { Nuclear factor- } \kappa \text { B } \\ \text { MAPK: } & \text { Mitogen-activated protein kinase } \\ \text { AKT: } & \text { Protein kinase B } \\ \text { CRCs: } & \text { Colorectal cancer cells } \\ \text { GECs: } & \text { Gingival epithelial cells } \\ \text { HSD: } & \text { Honestly significant difference. }\end{array}$

\section{Data Availability}

All raw RNA-seq data are accessible through GEO series accession number, GSE118691. Other data from Materials and Methods used to support the findings of this study are included in the article. If any other data are needed, please contact the corresponding author.

\section{Conflicts of Interest}

The authors indicate no potential conflicts of interest.

\section{Authors' Contributions}

FQ and HKL conceived, designed, and supervised this study, and KWY and ZZW collected the samples. KWY, TD, and $\mathrm{GH}$ performed the experiments. KWY and JZL analyzed and interpreted the data. KWY and FQ wrote the paper. All authors commented on the manuscript.

\section{Acknowledgments}

We appreciate the volunteers who provided the samples. We thank Professor Shili Liu and other colleagues in our laboratory for all of the kind advice and support. We thank the Natural Science Foundation of Shandong Province (Nos. ZR201702190185 and 2018GSF118231), the National Natural Science Foundation of China (No. 81630072), the Construction Engineering Special Foundation of "Taishan Scholars" of Shandong Province (No. tsqn20161068), and the Program of Qilu Young Scholars of Shandong University for the financial support.

\section{Supplementary Materials}

Supplementary 1. Table 1: primer sequences for quantitative real-time PCR (qRT-PCR).

Supplementary 2. Table 2: the clean reads of 54 samples after RNA-seq.

Supplementary 3. Table 3: genome mapping ratio summary of 54 samples.

Supplementary 4. Table 4: gene mapping ratio summary of 54 samples.

Supplementary 5. Table 5: top five enriched GO terms in the biological process for the 62 DEGs.

Supplementary 6. Figure 1: PCA of 54 samples of RNA-seq analyses. 
Supplementary 7. Figure 2: GO analysis of the 62 overlapped DEGs after F. nucleatum stimulation at $2 \mathrm{~h}, 6 \mathrm{~h}, 12 \mathrm{~h}, 24 \mathrm{~h}$, and $48 \mathrm{~h}$.

Supplementary 8. Figure 3: heat map summarizing the 18 overlapped DEGs from the GO biological process analysis after the five paired comparisons of cell proliferation.

Supplementary 9. Figure 4: (a) Flow cytometry analysis of cell apoptosis. (b) Heat map of the 3 overlapped DEGs from the GO biological process analysis after the five paired comparisons of cell apoptosis.

Supplementary 10. Figure 5: heat map of the 14 overlapping DEGs from the GO biological process analysis after the five paired comparisons of cell defense response.

Supplementary 11. Figure 6: (a) The protein levels of p53, phosphorylated p53 (p-p53). (b) The ratio of p-p53 and p53.

Supplementary 12. Figure 7: the Pathview analysis of the PI3K-AKT signaling pathway.

Supplementary 13. Figure 8: the Pathview analysis of MAPK signaling pathway.

Supplementary 14. Figure 9: the relative gene expression level of Bcl-2 (a), COX2(b), A20 (c), I $\kappa \mathrm{B} \alpha$ (d), and MIP2 (e) by qRT-PCR.

Supplementary 15. Figure 10: the Pathview analysis of the apoptosis signaling pathway.

Supplementary 16. Figure 11: the relative gene expression level of TRAILR2 (a), NOXA (b), PUMA (c), tubulin (d), actin (e), fodrin (f), and PARP (g) by RT-PCR.

\section{References}

[1] J. M. Albandar and E. M. B. Tinoco, "Global epidemiology of periodontal diseases in children and young persons," Periodontology 2000, vol. 29, no. 1, pp. 153-176, 2002.

[2] G. Thornton-Evans, P. Eke, L. Wei et al., "Periodontitis among adults aged $\geq 30$ years - United States, 2009-2010," MMWR Supplement, vol. 62, pp. 129-135, 2013.

[3] A. Di Benedetto, I. Gigante, S. Colucci, and M. Grano, "Periodontal disease: linking the primary inflammation to bone loss," Clinical and Developmental Immunology, vol. 2013, Article ID 503754, 17 pages, 2013.

[4] R. P. Darveau, "Periodontitis: a polymicrobial disruption of host homeostasis," Nature Reviews Microbiology, vol. 8, no. 7, pp. 481-490, 2010.

[5] R. Saini, P. P. Marawar, S. Shete, and S. Saini, "Periodontitis, a true infection," Journal of Global Infectious Diseases, vol. 1, no. 2, pp. 149-150, 2009.

[6] S. Emani, G. V. Gunjiganur, and D. S. Mehta, "Determination of the antibacterial activity of simvastatin against periodontal pathogens, Porphyromonas gingivalis and Aggregatibacter actinomycetemcomitans: an in vitro study," Contemporary Clinical Dentistry, vol. 5, no. 3, pp. 377382, 2014.

[7] J. Liu, J. Zhao, C. Li, N. Yu, D. Zhang, and Y. Pan, "Clinical and microbiologic effect of nonsurgical periodontal therapy on patients with chronic or aggressive periodontitis," Quintessence International, vol. 44, no. 8, pp. 575-583, 2013.
[8] N. M. O'Brien-Simpson, P. D. Veith, S. G. Dashper, and E. C. Reynolds, "Antigens of bacteria associated with periodontitis," Periodontology 2000, vol. 35, no. 1, pp. 101-134, 2004.

[9] Y. Takeuchi, M. Umeda, M. Sakamoto, Y. Benno, Y. Huang, and I. Ishikawa, "Treponema socranskii, Treponema denticola, and Porphyromonas gingivalis are associated with severity of periodontal tissue destruction," Journal of Periodontology, vol. 72, no. 10, pp. 1354-1363, 2001.

[10] B. Signat, C. Roques, P. Poulet, and D. Duffaut, "Fusobacterium nucleatum in periodontal health and disease," Current Issues in Molecular Biology, vol. 13, no. 2, pp. 25-36, 2011.

[11] P. I. Diaz, P. S. Zilm, and A. H. Rogers, "Fusobacterium nucleatum supports the growth of Porphyromonas gingivalis in oxygenated and carbon-dioxide-depleted environments," Microbiology, vol. 148, no. 2, pp. 467-472, 2002.

[12] W. E. C. Moore and L. V. H. Moore, "The bacteria of periodontal diseases," Periodontology 2000, vol. 5, no. 1, pp. 6677, 1994.

[13] A. Kai, F. Cooke, N. Antoun, C. Siddharthan, and O. Sule, "A rare presentation of ventriculitis and brain abscess caused by Fusobacterium nucleatum," Journal of Medical Microbiology, vol. 57, no. 5, pp. 668-671, 2008.

[14] K. Wijarnpreecha, N. Yuklyaeva, S. Sornprom, and C. Hyman, "Fusobacterium nucleatum: atypical organism of pyogenic liver abscess might be related to sigmoid diverticulitis," North American Journal of Medical Sciences, vol. 8, no. 4, pp. 197199, 2016.

[15] F. Bytyci and E. Khromenko, "Hepatic abscess caused by Fusobacterium necrophorum after a trip to the dentist," BMJ Case Reports, vol. 2016, 2016.

[16] K. Nagaoka, K. Yanagihara, Y. Morinaga, and S. Kohno, "Detection of Fusobacterium nucleatum in two cases of empyema and lung abscess using paromomycin-vancomycin supplemented Brucella HK agar," Anaerobe, vol. 43, pp. 99-101, 2017.

[17] E. Kroon, N. A. Arents, and F. J. Halbertsma, "Septic arthritis and osteomyelitis in a 10-year-old boy, caused by Fusobacterium nucleatum, diagnosed with PCR/16S ribosomal bacterial DNA amplification," BMJ Case Reports, vol. 2012, no. 1, article bcr1220115335, 2012.

[18] A. McKinnon, A. Y. Black, K. Lortie, and N. A. Fleming, "A case of adolescent pelvic inflammatory disease caused by a rare bacterium: Fusobacterium nucleatum," Journal of Pediatric and Adolescent Gynecology, vol. 26, no. 6, pp. e113-e115, 2013.

[19] A. B. Kruse, A. C. Kuerschner, M. Kunze et al., "Association between high risk for preterm birth and changes in gingiva parameters during pregnancy-a prospective cohort study," Clinical Oral Investigations, vol. 22, no. 3, pp. 1263-1271, 2018.

[20] Y. W. Han, Y. Fardini, C. Chen et al., "Term stillbirth caused by oral Fusobacterium nucleatum," Obstetrics \& Gynecology, vol. 115, pp. 442-445, 2010.

[21] Y. W. Han, T. Shen, P. Chung, I. A. Buhimschi, and C. S. Buhimschi, "Uncultivated bacteria as etiologic agents of intra-amniotic inflammation leading to preterm birth," Journal of Clinical Microbiology, vol. 47, no. 1, pp. 38-47, 2009.

[22] J. H. Jeng, C. P. Chan, Y. S. Ho, W. H. Lan, C. C. Hsieh, and M. C. Chang, "Effects of butyrate and propionate on the adhesion, growth, cell cycle kinetics, and protein synthesis of cultured human gingival fibroblasts," Journal of Periodontology, vol. 70, no. 12, pp. 1435-1442, 1999. 
[23] P. M. Bartold, N. J. Gully, P. S. Zilm, and A. H. Rogers, "Identification of components in Fusobacterium nucleatum chemostat-culture supernatants that are potent inhibitors of human gingival fibroblast proliferation," Journal of Periodontal Research, vol. 26, no. 4, pp. 314-322, 1991.

[24] M. R. Rubinstein, X. Wang, W. Liu, Y. Hao, G. Cai, and Y. W. Han, "Fusobacterium nucleatum promotes colorectal carcinogenesis by modulating E-cadherin/ $\beta$-catenin signaling via its FadA adhesin," Cell Host \& Microbe, vol. 14, no. 2, pp. 195-206, 2013.

[25] S. Ji, J. E. Shin, Y. S. Kim, J. E. Oh, B. M. Min, and Y. Choi, “Tolllike receptor 2 and NALP2 mediate induction of human betadefensins by Fusobacterium nucleatum in gingival epithelial cells," Infection and Immunity, vol. 77, no. 3, pp. 1044-1052, 2009.

[26] L. Yin and W. O. Chung, "Epigenetic regulation of human $\beta$ defensin 2 and CC chemokine ligand 20 expression in gingival epithelial cells in response to oral bacteria," Mucosal Immunology, vol. 4, no. 4, pp. 409-419, 2011.

[27] Y. W. Han, W. Shi, G. T. J. Huang et al., "Interactions between periodontal bacteria and human oral epithelial cells: Fusobacterium nucleatum adheres to and invades epithelial cells," Infection and Immunity, vol. 68, no. 6, pp. 3140-3146, 2000.

[28] E. K. Fawzy El-Sayed and C. E. Dörfer, "Gingival mesenchymal stem/progenitor cells: a unique tissue engineering gem," Stem Cells International, vol. 2016, Article ID 7154327, 16 pages, 2016.

[29] M. Phillipson and P. Kubes, "The neutrophil in vascular inflammation," Nature Medicine, vol. 17, no. 11, pp. 13811390, 2011.

[30] P. L. Wang, K. Ohura, T. Fujii et al., "DNA microarray analysis of human gingival fibroblasts from healthy and inflammatory gingival tissues," Biochemical and Biophysical Research Communications, vol. 305, no. 4, pp. 970-973, 2003.

[31] A. C. F. Morandini, C. R. Sipert, T. H. Gasparoto et al., "Differential production of macrophage inflammatory protein- $1 \alpha$, stromal-derived factor-1, and IL- 6 by human cultured periodontal ligament and gingival fibroblasts challenged with lipopolysaccharide from P. gingivalis," Journal of Periodontology, vol. 81, no. 2, pp. 310-317, 2010.

[32] S.-H. Ahn, S. M. Chun, C. Park, J. H. Lee, S. W. Lee, and T. H. Lee, "Transcriptome profiling analysis of senescent gingival fibroblasts in response to Fusobacterium nucleatum infection," PLoS One, vol. 12, no. 11, article e188755, 2017.

[33] T. Ara, K. Kurata, K. Hirai et al., "Human gingival fibroblasts are critical in sustaining inflammation in periodontal disease," Journal of Periodontal Research, vol. 44, no. 1, pp. 21-27, 2009.

[34] A. Rasul, R. Bao, M. Malhi et al., "Induction of apoptosis by costunolide in bladder cancer cells is mediated through ROS generation and mitochondrial dysfunction," Molecules, vol. 18, no. 2, pp. 1418-1433, 2013.

[35] B. Tang, K. Wang, Y. P. Jia et al., "Fusobacterium nucleatuminduced impairment of autophagic flux enhances the expression of proinflammatory cytokines via ROS in Caco-2 cells," PLoS One, vol. 11, no. 11, article e165701, 2016.

[36] O. Leavy, "Inflammation: regulating ROS," Nature Reviews Immunology, vol. 14, no. 6, p. 357, 2014.

[37] D. Kim, B. Langmead, and S. L. Salzberg, "HISAT: a fast spliced aligner with low memory requirements," Nature Methods, vol. 12, no. 4, pp. 357-360, 2015.
[38] B. Langmead and S. L. Salzberg, "Fast gapped-read alignment with Bowtie 2," Nature Methods, vol. 9, no. 4, pp. 357-359, 2012.

[39] B. Li and C. N. Dewey, "RSEM: accurate transcript quantification from RNA-seq data with or without a reference genome," BMC Bioinformatics, vol. 12, no. 1, p. 323, 2011.

[40] J. Ye, L. Fang, H. Zheng et al., "WEGO: a web tool for plotting GO annotations," Nucleic Acids Research, vol. 34, no. Web Server, pp. W293-W297, 2006.

[41] M. Kanehisa, M. Araki, S. Goto et al., "KEGG for linking genomes to life and the environment," Nucleic Acids Research, vol. 36, no. Database issue, pp. D480-D484, 2008.

[42] C. von Mering, L. J. Jensen, B. Snel et al., "STRING: known and predicted protein-protein associations, integrated and transferred across organisms," Nucleic Acids Research, vol. 33, no. Database issue, pp. D433-D437, 2005.

[43] W. Luo and C. Brouwer, "Pathview: an R/Bioconductor package for pathway-based data integration and visualization," Bioinformatics, vol. 29, no. 14, pp. 1830-1831, 2013.

[44] D. F. Kinane, "Causation and pathogenesis of periodontal disease," Periodontology 2000, vol. 25, no. 1, pp. 8-20, 2001.

[45] P. I. Eke, B. A. Dye, L. Wei et al., "Update on prevalence of periodontitis in adults in the United States: NHANES 2009 to 2012," Journal of Periodontology, vol. 86, no. 5, pp. 611622,2015

[46] J. Mysak, S. Podzimek, P. Sommerova et al., "Porphyromonas gingivalis: major periodontopathic pathogen overview," Journal of Immunology, vol. 2014, Article ID 476068, 8 pages, 2014.

[47] Z. Metzger, Y. Y. Lin, F. Dimeo, W. W. Ambrose, M. Trope, and R. R. Arnold, "Synergistic pathogenicity of Porphyromonas gingivalis and Fusobacterium nucleatum in the mouse subcutaneous chamber model," Journal of Endodontics, vol. 35, no. 1, pp. 86-94, 2009.

[48] Y. Yang, W. Weng, J. Peng et al., "Fusobacterium nucleatum increases proliferation of colorectal cancer cells and tumor development in mice by activating toll-like receptor 4 signaling to nuclear factor- $\kappa \mathrm{B}$, and up-regulating expression of microRNA-21," Gastroenterology, vol. 152, no. 4, pp. 851-866.e24, 2017.

[49] D. Siegmund, I. Lang, and H. Wajant, "Cell deathindependent activities of the death receptors CD95, TRAILR1 and TRAILR2," The FEBS Journal, vol. 284, no. 8, pp. 11311159, 2017.

[50] J. Wang, D. Cui, S. Gu et al., "Autophagy regulates apoptosis by targeting NOXA for degradation," Biochimica et Biophysica Acta (BBA) - Molecular Cell Research, vol. 1865, no. 8, pp. 1105-1113, 2018.

[51] P. K. Panda, P. P. Naik, B. R. Meher et al., "PUMA dependent mitophagy by Abrus agglutinin contributes to apoptosis through ceramide generation," Biochimica et Biophysica Acta (BBA) - Molecular Cell Research, vol. 1865, no. 3, pp. 480495,2018

[52] W. T. Chang, W. Liu, Y. H. Chiu et al., "A 4-phenoxyphenol derivative exerts inhibitory effects on human hepatocellular carcinoma cells through regulating autophagy and apoptosis accompanied by downregulating $\alpha$-tubulin expression," Molecules, vol. 22, no. 5, p. 854, 2017.

[53] N. Aida, T. Ushikubo, F. Kobayashi et al., "Actin stabilization induces apoptosis in cultured porcine epithelial cell rests of Malassez," International Endodontic Journal, vol. 49, no. 7, pp. 663-669, 2016. 
[54] J. Lee, S. Mun, A. Park, D. Kim, B. Heun Cha, and H. G. Kang, "Bicalutamide enhances fodrin-mediated apoptosis through calpain in LNCaP," Experimental Biology and Medicine, vol. 243, no. 10, pp. 843-851, 2018.

[55] H. Luo, H. Liang, J. Chen et al., "Hydroquinone induces TK6 cell growth arrest and apoptosis through PARP-1/p53 regulatory pathway," Environmental Toxicology, vol. 32, no. 9, pp. 2163-2171, 2017.

[56] M. S. Tonetti, M. A. Imboden, L. Gerber, N. P. Lang, J. Laissue, and C. Mueller, "Localized expression of mRNA for phagocyte-specific chemotactic cytokines in human periodontal infections," Infection and Immunity, vol. 62, no. 9, pp. 4005-4014, 1994.

[57] S. H. Ahn, S. H. Cho, J. E. Song et al., "Caveolin-1 serves as a negative effector in senescent human gingival fibroblasts during Fusobacterium nucleatum infection," Molecular Oral Microbiology, vol. 32, no. 3, pp. 236-249, 2017.

[58] S. H. Ahn, J. E. Song, S. Kim et al., "NOX1/2 activation in human gingival fibroblasts by Fusobacterium nucleatum facilitates attachment of Porphyromonas gingivalis," Archives of Microbiology, vol. 198, no. 6, pp. 573-583, 2016.

[59] F. Q. Bui, L. Johnson, J. Roberts et al., "Fusobacterium nucleatum infection of gingival epithelial cells leads to NLRP3 inflammasome-dependent secretion of IL- $1 \beta$ and the danger signals ASC and HMGB1," Cellular Microbiology, vol. 18, no. 7, pp. 970-981, 2016.

[60] S.-C. Hung, P. R. Huang, C. L. C. Almeida-da-Silva, K. R. Atanasova, O. Yilmaz, and D. M. Ojcius, "NLRX1 modulates differentially NLRP3 inflammasome activation and NF- $\kappa$ B signaling during Fusobacterium nucleatum infection," Microbes and Infection, vol. 20, no. 9-10, pp. 615-625, 2018.

[61] M. Wada, D. Canals, M. Adada et al., "P38 delta MAPK promotes breast cancer progression and lung metastasis by enhancing cell proliferation and cell detachment," Oncogene, vol. 36, no. 47, pp. 6649-6657, 2017.

[62] Z. F. Liu, D. Zheng, G. C. Fan, T. Peng, and L. Su, "Heat stress prevents lipopolysaccharide-induced apoptosis in pulmonary microvascular endothelial cells by blocking calpain/p38 MAPK signalling," Apoptosis, vol. 21, no. 8, pp. 896-904, 2016.

[63] L. B. Zhang, Z. T. Man, W. Li, W. Zhang, X. Q. Wang, and S. Sun, "Calcitonin protects chondrocytes from lipopolysaccharide-induced apoptosis and inflammatory response through MAPK/Wnt/NF- $\kappa$ B pathways," Molecular Immunology, vol. 87, pp. 249-257, 2017.

[64] L. Drukker, A. Margulis, M. Chaouat, R. Levitzki, E. Maiorenko, and H. Ben Bassat, "Changes of PI3K/AKT/BCL2 signaling proteins in congenital giant nevi: melanocytes contribute to their increased survival and integrity," Journal of Receptor and Signal Transduction Research, vol. 33, no. 6, pp. 359-366, 2013.

[65] E. Zeldich, R. Koren, C. Nemcovsky, and M. Weinreb, "Enamel matrix derivative stimulates human gingival fibroblast proliferation via ERK," Journal of Dental Research, vol. 86, no. 1, pp. 41-46, 2007.

[66] H. J. Chae, M. S. Ha, D. H. Yun et al., "Mechanism of cyclosporine-induced overgrowth in gingiva," Journal of Dental Research, vol. 85, no. 6, pp. 515-519, 2006.

[67] B. C. Heng, X. Ye, Y. Liu, W. L. Dissanayaka, G. S. P. Cheung, and C. Zhang, "Effects of recombinant overexpression of Bcl2 on the proliferation, apoptosis, and osteogenic/odontogenic differentiation potential of dental pulp stem cells," Journal of Endodontia, vol. 42, no. 4, pp. 575-583, 2016.
[68] L. L. Eftang, Y. Esbensen, T. M. Tannæs, I. R. K. Bukholm, and G. Bukholm, "Interleukin- 8 is the single most up-regulated gene in whole genome profiling of $H$. pylori exposed gastric epithelial cells," BMC Microbiology, vol. 12, no. 1, p. 9, 2012.

[69] V. T. Baron, R. Pio, Z. Jia, and D. Mercola, "Early growth response 3 regulates genes of inflammation and directly activates IL6 and IL8 expression in prostate cancer," British Journal of Cancer, vol. 112, no. 4, pp. 755-764, 2015.

[70] R. S. Morton and A. I. Dongari-Bagtzoglou, "Cyclooxygenase2 is upregulated in inflamed gingival tissues," Journal of Periodontology, vol. 72, no. 4, pp. 461-469, 2001.

[71] K. Noguchi, M. Shitashige, and I. Ishikawa, "Involvement of cyclooxygenase- 2 in interleukin- $1 \alpha$-induced prostaglandin production by human periodontal ligament cells," Journal of Periodontology, vol. 70, no. 8, pp. 902-908, 1999. 


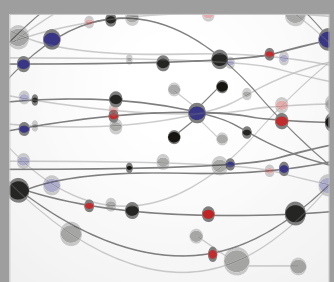

The Scientific World Journal
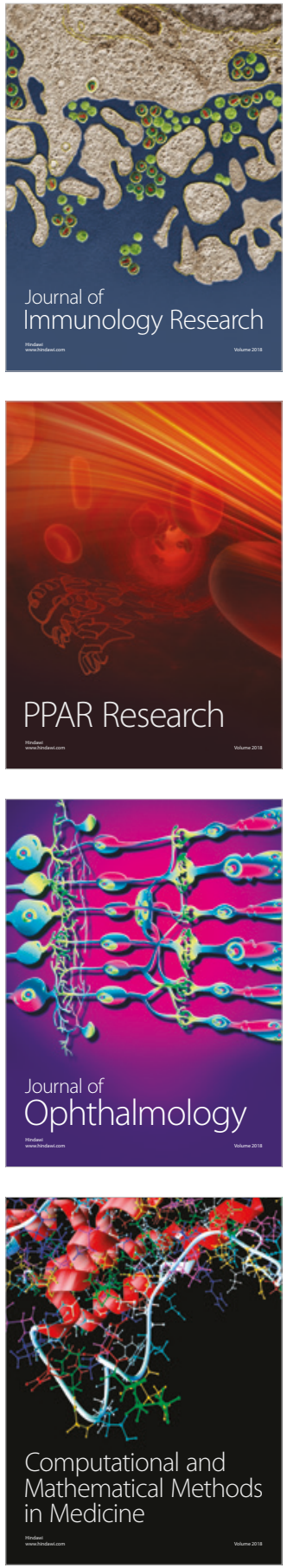

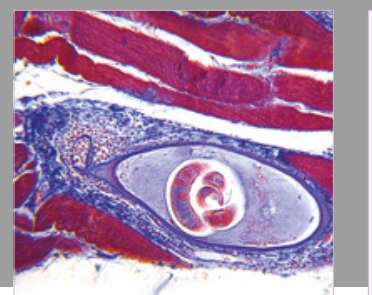

Gastroenterology Research and Practice

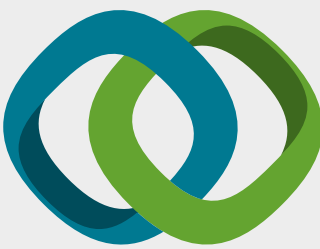

\section{Hindawi}

Submit your manuscripts at

www.hindawi.com
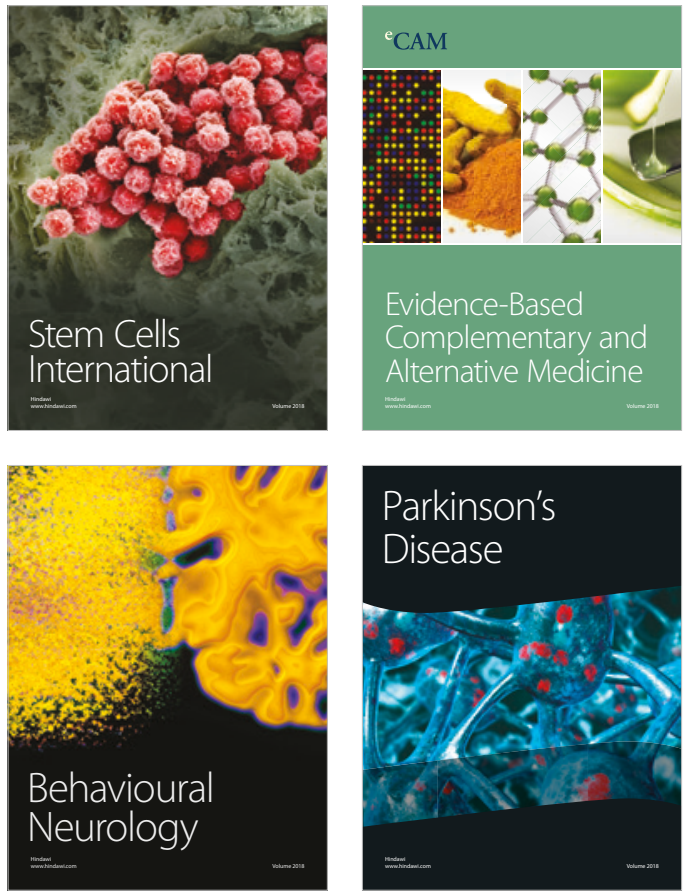

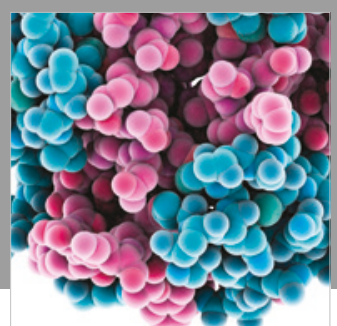

ournal of

Diabetes Research

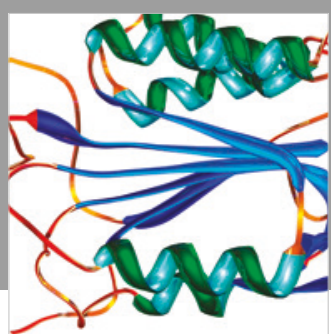

Disease Markers
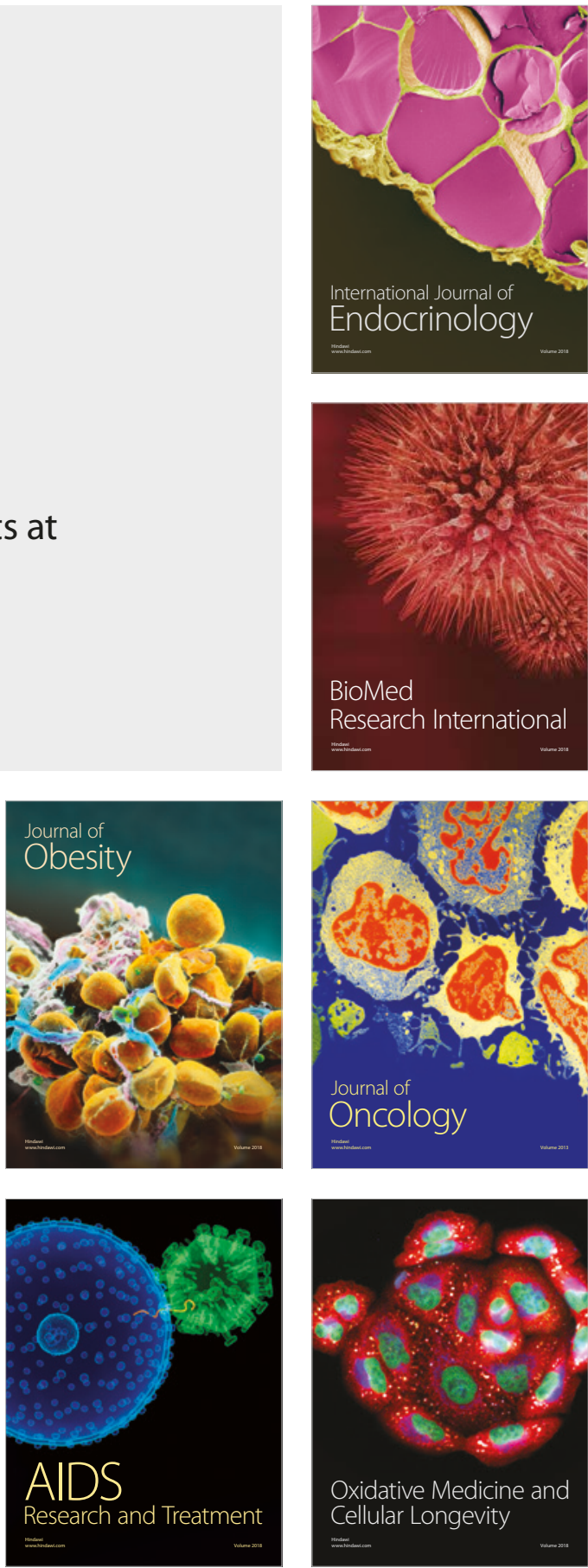